WFPS-TME-090

\title{
MASTER
}

MAY 23, 1978

\section{TRITIUM BREEDING IN A FUSION-FISSION HYBRID BREEDER REACTOR}

\author{
JOHN R, MCCOWAN \\ PENNSYLVANIA STATE UNIVERSITY
}

COOPERATIVE GRADUATE EDUCATION PROGRAM IN FUSION TECHNOLOGY

ADMINISTERED FOR THE U.S. DEPARTMENT OF ENERGY

BY THE WESTINGHOUSE ELECTRIC CORPORATION

CONTRACT EG-77-C-02-4231-A000 


\section{DISCLAIMER}

This report was prepared as an account of work sponsored by an agency of the United States Government. Neither the United States Government nor any agency Thereof, nor any of their employees, makes any warranty, express or implied, or assumes any legal liability or responsibility for the accuracy, completeness, or usefulness of any information, apparatus, product, or process disclosed, or represents that its use would not infringe privately owned rights. Reference herein to any specific commercial product, process, or service by trade name, trademark, manufacturer, or otherwise does not necessarily constitute or imply its endorsement, recommendation, or favoring by the United States Government or any agency thereof. The views and opinions of authors expressed herein do not necessarily state or reflect those of the United States Government or any agency thereof. 


\section{DISCLAIMER}

Portions of this document may be illegible in electronic image products. Images are produced from the best available original document. 


\section{ACKNOWLEDGEMENT}

This work was performed for the U.S. Department of Energy, under Contract EG-77-C-02-4231-A000, Cooperative Graduate Education Program in Fusion Technology. Reproduction, translation, publication, use and disposal, in whole or in part, by or for the United States Government is permitted.

\section{LEGAL NOTICE}

This report was prepared as an account of Government sponsored work. Neither the United States, nor the Administration, nor any person acting on behalf of the Administration:

A. Makes any warranty or representation, expressed or implied, with respect to the accuracy, completeness, or usefulness of the information contained in this report, or that the use of any information, apparatus, method or process disclosed in this report may not infringe privately owned rights; or

B. Assumes any liabilities with respect to the use of, or for damages resulting from the use of any information, apparatus, method, or process disclosed in this report. 
WFPS-TME-090

MAY 23, 1978

\section{IIRITIUM BREEDING IN A FUSION-FISSION HYBRID BREEDER REACTOR}

PREPARED BY :

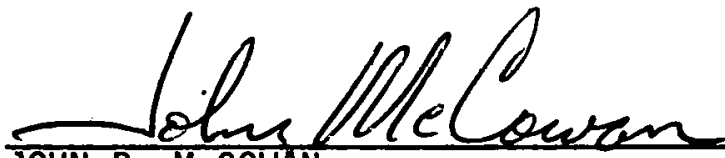

JOHN R. MCCOWAN

GRADUATE STUDENT PROGRAM PARTICIPANT

PENNSYLVANIA STATE UNIVERSITY

ReVIEWED BY: $\frac{\text { GORDON GIBSdT, MANAGER }}{\text { NUCLEAR AND PLASMA ENGINEERING }}$

APPROVED BY:
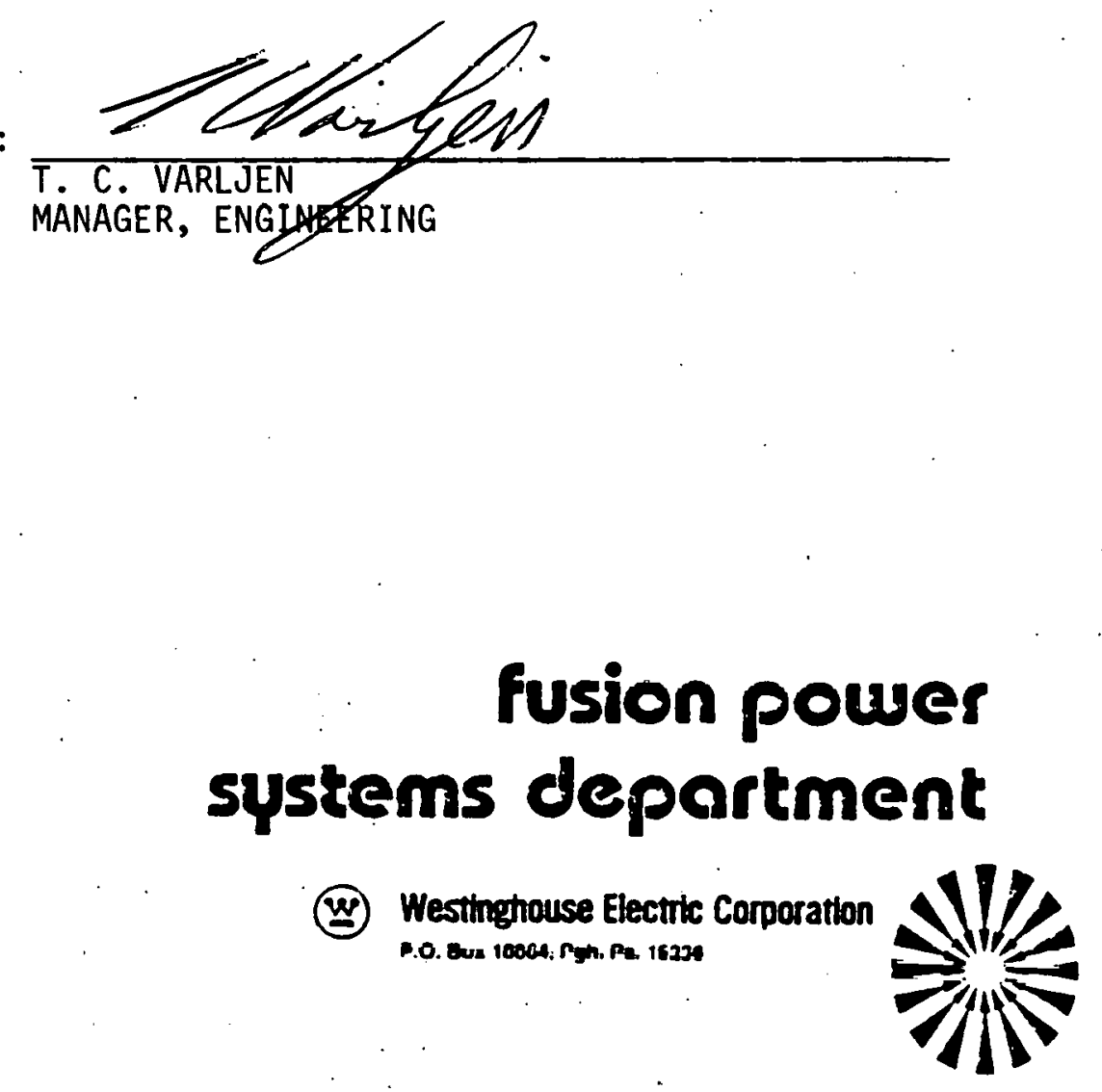


\section{ABSTRACT}

In order to construct a D-T fusion-fission hybrid breeder reactor there must be some guarantee that tritium will be available to fuel the fusion reaction. This can be achieved by breeding tritium in the blanket of the reactor. A variety of blanket configurations have been studied with the intent of arriving at a blanket design capable of attaining sizeable values of power and fissile fuel production, and simultaneously assure self-sufficiency in tritium production for the reactor, i.e., a T-breeding ratio greater than 1.0.

Using a four group diffusion theory code, a number of possible blanket configurations were studied during the parametric phase of hybrid breeder blanket design. They included tritium breeding zones of natural or enriched lithium metal and natural lithium in dilithium oxide, neutron multiplier zones of uranium and thorium with varying amounts of plutonium, thorium fissile breeding zones (sometimes containing plutonium), and graphite reflector zones. The choice of clad used in the fuel rods has also been found to influence tritium breeding.

One of the more promising designs studied combines a tritium breeding ratio of 1.2 wilh a blanket fissile power of $16 \mathrm{GW}(\mathrm{th})$, and a U-233 production rate of 2.7 tonnes per year. 
TABLE OF CONTENTS

Section No.

Page No.

$\begin{array}{llr}\text { I } & \text { INTRODUCTION } & \text { I-1 } \\ \text { II } & \text { COMPUTATIONAL TECHNIQUES AND PRELIMINARY RESULTS } & \text { II -1 } \\ \text { II } & \text { REFERENCE CASE CRITERIA AND RESULTS } & \text { III I - } \\ \text { IV } & \text { DISCUSSION OF RESULTS } & \text { IV-1 } \\ \text { V } & \text { SUMMARY } & \text { V-1 } \\ & \text { ACKNOWLEDGEMENT } & \text { V-3 } \\ \text { VI } & \text { REFERENCES } & \text { VI }-1\end{array}$




\section{LIST OF FIGURES}

Figure No.

Page No.

I-1 General Hybrid Breeder Reactor Geometry (Top View)

I-2 Fuel Lattice Description (View Along Minor Plasma Radius)

II-1 Tritium Breeding Ratio Vs. a/o $\mathrm{Pu}$ and $\mathrm{Pu}$ Zone Width for Design \#1

III-1 TBR in a $\mathrm{Li}-(T h, \mathrm{Pu}) \mathrm{C}-\mathrm{ThC}-\mathrm{C}$ Blanket $\mathrm{Vs}, \mathrm{a} / \mathrm{O} \mathrm{Pu}$ and $(\mathrm{Th}, \mathrm{Pu}) \mathrm{C}$ Zone Width, at $23.86 \mathrm{a} / 0 \mathrm{Li}-6$ in $\mathrm{Li}$.

III-2 TBR in a Li-(Th,Pu)C-ThC-C Blanket Vs. a/o Pu and a/o $\mathrm{Li}-6$ in Li. (Th, Pu)C Zone Width is $6 \mathrm{~cm}$.

III -6

III-3 Fissile Power in a $\mathrm{Li}-(\mathrm{Th}, \mathrm{Pu}) \mathrm{C}-\mathrm{ThC}-\mathrm{C}$ Blanket Vs. a/o $\mathrm{Pu}$ and $(\mathrm{Th}, \mathrm{Pu}) \mathrm{C}$ Zone Width, at $23.86 \mathrm{a} / 0 \mathrm{Li}-6$ in $\mathrm{Li}$.

III-4 U-233 Production in a $\mathrm{Li}-(\mathrm{Th}, \mathrm{Pu}) \mathrm{C}-\mathrm{ThC}-\mathrm{C}$ Blanket Vs. a/O and (Th, Pu)C Zone Width, at $23.86 \mathrm{a} / 0 \mathrm{Li}-6$ in Li.

III-5 TBR in a Li-(U,Pu)C-ThC Blanket Vs. a/o Pu and $(\mathrm{U}, \mathrm{Pu}) \mathrm{C}$ Zone Width, at $0.5 \mathrm{a} / 0 \mathrm{U}-235$ in $\mathrm{U}$.

III-6 Pu Consumption in a $\mathrm{Li}-(\mathrm{U}, \mathrm{Pu}) \mathrm{C}-\mathrm{ThC} \mathrm{Blanket} \mathrm{Vs}$. a/o $\mathrm{Pu}$ and $(11, \mathrm{P}(\mathrm{U}) \mathrm{C}$. Zone Width, at $0.5 \mathrm{a} / 0 \mathrm{U}-235$ in $U$.

III-7 Fissile Power in a Li-(U,Pu)C-ThC Blanket Vs. a/O Pu and $(\mathrm{U}, \mathrm{PU}) \mathrm{C}$ Zone Width, at $0.5 \mathrm{a} / 0 \mathrm{U}-235$ in $U$.

III-8 U-233 Production in a Li- $(U, P u) C-T h C$ Blanket Vs. a/o $\mathrm{Pu}$ and $(\mathrm{U}, \mathrm{Pu}) \mathrm{C}$ Zone Width, at $0.5 \mathrm{a} / \mathrm{O} U-235$ in $U$.

TBR in a $(U, P u) C-(T h, P u) C-L_{2}{ }^{O}-C$ Blanket Vs. a/o $\mathrm{Pu}$ in $(\mathrm{U}, \mathrm{Pu}) \mathrm{C}$ and $(\mathrm{U}, \mathrm{Pu}) \mathrm{C}$ Zone Width.

III-10 Pu Consumption in a $(U, P u) C-(T h, P u) C-L_{2} \mathrm{O}_{2}-\mathrm{C}$ Blanket Vs. $\mathrm{a} / \mathrm{O} \mathrm{Pu}$ in $(\mathrm{U}, \mathrm{Pu}) \mathrm{C}$ and $(\mathrm{U}, \mathrm{Pu}) \mathrm{C}$ Zone Width.

III-il Fissile Power in a $(U, P u) C-T h, P u) C-L i 20-C$ Blanket Vs. $\mathrm{a} / \mathrm{O} \mathrm{Pu}$ in $(\mathrm{U}, \mathrm{Pu}) \mathrm{C}$ and $(\mathrm{U}, \mathrm{Pu}) \mathrm{C}$ Zone Width.

III-12 U-233 Production in a $(U, P u) C-(T h, P u) C-L i 20-C$ Blanket Vs. $\mathrm{a} / \mathrm{O} \mathrm{Pu}$ in $(\mathrm{U}, \mathrm{Pu}) \mathrm{C}$ and $(\mathrm{U}, \mathrm{Pu}) \mathrm{C}$ Zone Width.

IV-1 Tritium Breeding Cross Sections and Blanket Neutron Flux Spectrum Vs. Energy 
Table No.

Page No.

I-1 FUEL LATTICE. SPECIFICATIONS

II-1 EXAMPLE OF THE THREE VARIABLE CENTRAL COMPOSITE DESIGN VALUES

II-2. EXAMPLE OF THE COMBINATIONS FOR A THREE VARIABLE CENTRAL COMPOSITE BESIGN

II -4

II-3 DESIGN \# 1 EXAMPLE OF PERTINENT DATA

I I -7

II-4a LISTING OF BLANKET DESIGNS CONSIDERED

I I -10

I I $-4 b$

LISTING OF BLANKET DESIGNS CONSIDERED

I I - 11

I I $-4 \mathrm{C}$

LISTING OF BLANKET DESIGNS CONSIDERED

II -12

I I I - 7

COMPILATION OF DATA LEADING TO REFERENCE CASE \#1

I I I -4

III -2

COMPILATION OF DATA LEADING TO REFERENCE CASE \#2

I I I -9

I I I -3

COMPILATION OF DATA. LEADING TO REFERENCE CASE \#3

II I - 14

I I I -4

SUMMARY OF REFERENCE CASE DATA

I I I -19

IV-1 TRITIUM BREEDING CROSS SECTIONS OF LITHIUM BLANKET SPECTRUM AVERAGED BY ANISN

IV -4 


\section{INTRODUCTION}

At present the most promising fusion reaction is that of deuterium and tritium. The occurrence of a. $14 \mathrm{Mev}$ neutron from the reaction is fortunate since tritium does not exist naturally, but can be created by neutron induced reactions with Li-6 and Li-7. The first commercial fusion reactors may, therefore, have a plasma zone surrounded or partially: surrounded by a lithium containing blanket. Problems with control and containment of the plasma in magnetically confined reactors impose design requirements on the power production by the fusion reactor in addition to that of tritium production. In an effort to lessen the constraints imposed on the fusion reactor and enhance power production, the use of a fissile breeding blanket was suggested by the U.S. Atomic Energ: Cormission's program in controlled nuclear research in 1951 (Ref. 71 ). "The results presented in this paper pertain to the blanket of a fusion-fission hybrid breeder reactor, which was under study at Westinghouse's Fusion Power Systems Department prior to october of 1977.

The performance requirements imposed on the blanket will ultimately reflect the way the hybrid breeder will fit into the total energy production system of the area where it is to be built. Since the exact conditions under which the hybrid breeder will enter the energy picture are unknown, the requirements chosen for the blankets in this study were imposed as a basis on which:calculations and preliminary design work could proceed. The four requirements arbitrarily established for the hybrid breeder àre presented below. 
The first of these is that the reactor be self-sufficient in tritium production. Since there are no major civilian facilities in existence for the production of tritium, consideration of selfsufficiency in tritium production seems a logical requirement for the first hybrid breeder. Fortesque (Ref \#2) argues that optimization of the performance of fission and fusion reactors should occur together. He concludes that tritium breeding may be easier in the fission reactors than in the hybrid reactor. The observation that this mutual arrangement could be more efficient is recognized; however, logistic and safety considerations make it desirable to design for self-sufficient in-plant tritium production. The calculations of the tritium breeding required for a reactor onefifth the size of the hybrid breeder appear in reference $\# 3$, and specify a tritium breeding ratio (TBR) of 1.16 , corresponding to approximately $100 \mathrm{~kg}$ of tritium produced per vear, for the reactor under consideration. The value of 1.16 rather than 1.0 , for the TBR, takes into account loss of tritium in handling and to radioactive decay。

The second requirement; set on the hybrid breeder blanket considered here, is to produce enough fissile fuel to supply five fission reactors of high conversion ratio, each using $180 \mathrm{~kg}$ makeup fissile material per year. The reactions available for fissile production are the conversion of $\mathrm{U}-238$ to $\mathrm{Pu}-239$ and the conversion of Th-232 to U-233 by capture reactions. Designs considered in this paper employ the thorium reaction to avoid proliferation of $\mathrm{Pu}-239$. In one scenario the $\mathrm{U}-233$ is mixed with depleted uranium, thus forming 
a reactor grade ( $3 \%$ fissile) fuel that would be difficult to transform to weapons grade material without the use of gaseous diffusion equipment to separate and concentrate the fissile isotopes. The arbitrary choice of five fission reactors, corresponding to 0.9 tonnes per year fissile production, may be subject to large changes as future fuel requirements become more specific. To reflect this uncertainty the value of 1.5 tonnes per year will be used as a goal. for fissile production.

The next requirement of the hybrid blanket is that it produce enough energy to power the hybrid breeder reactor, itself, and have power for sale. This implies that through the fast fission neutron multiplication within the blanket, enough thermal power be generated to supply, after conversion to electrical power, the neutral beams, magnetic field coils, auxilary systems, etc. This has been assumed to require $3 \mathrm{GW}(\mathrm{th})$. The blanket power is supplemerted by approximately $250 \mathrm{MW}(\mathrm{th})$ alpha particle power generated by the plasma. An ddaitional $3 \mathrm{GW}(\mathrm{th})$ is also assumed to be generated for sale to consumers. Thus, with a thermal to electrical conversion efficiency of $33 \%$, a fission power of 7 to $8 \mathrm{GW}(\mathrm{th})$ is set as a goal for the blanket. This power can be generated by blankets containing natural uranium or blankets enriched in plutonium obtained from the discharge of fission reactors. The composition of the discharge was assumed to be $69.7 \mathrm{a} / \mathrm{O} \mathrm{Pu}-239$ and $30.3 \mathrm{a} / \mathrm{O} \mathrm{Pu}-240$. Pu-241 was lumped with $\mathrm{Pu}-239$ and $\mathrm{Pu}-242$ with $\mathrm{Pu}-240$. Pu-239 also plays the role of a fast fission neutron multiplier, enhancing the neutron production in a machine that must produce one triton, some fissile fuel, and fissile power from one fusion neutron. 
The final requirement imposed on the hybrid breeder in this study is that of zero net plutonium production or consumption at the end of one year's irradiation. The fear of proliferation of weapons grade material, or a substance easily transformed to weapons grade material, is the reason for the requirement of zero net Pu-239 production, imposed on the hybrid as part of this study. With zero net consumption; the need for transportation of $\mathrm{Pu}$ to the reactor site, after initial loading, is avoided. Using the "same" plutonium from one loading to the next requires some sort of a reprocessing plant within the reactor facility. The reprocessing plant would be an added expense to the hybrid breeder project, however, stipulating zero plutonium production avoids the cost of purchasing Pu to replenish the blanket. Achievement of zero net $\mathrm{Pu}$ production (consumption) is accomplished by adding U-238 to the blanket in an amount that creates an equilibrium of $\mathrm{Pu}$ consuration and production. A more detailed discussion of the goals and the potential of a fusion-fission breeder is presented by Draper and Gage (Ref.4).

Early blanket designers recognized similar goals for their blankets, with the exception of zero plutonium production. Leonard (Ref.\#5) summarizes seven early (prior to 1965) design studies. None of these studies were very specific, however, they all require some form of uranium and recognize the fact that tritium should be bred using a compound of lithium. One interesting concept involves the use of enriched uranium in a $\mathrm{UO}_{2} \mathrm{SO}_{2}$ coolant. Thịs design, proposed by Barrett (Ref.\#6), approached criticality

$\therefore \quad \quad \quad \quad \quad \quad \quad \quad-4$


and bred tritium in regions outside the blanket by making use of the delayed fission neutrons.

The first of what Leonard terms the "moderd" fusion-fission hybrid concepts was developed by Lontai in a 1965 MIT thesis (Ref.\#7). Lontai!'s study considered two zone:blankets, a coolant zone and an attenuator zone. The coolant zone consisted of fused salts of lithium and beryllium (taking advantage of an $(n, 2 n)$ reaction in $\mathrm{Be})$. The outer attenuator zone contained the same fused salts plus some natural uranium in the form of $\mathrm{UF}_{4}$. The total width of Lontai!s blanket was approximately $50 \mathrm{~cm}$, and was able to produce adequate anounts of tritium and fissile fuel (in the form of $\mathrm{Pu}-239)$. However, power production was four times less than the reguirement set for the hybrid breeder studied here. Lontai's calculation also assumed an infinite slab wall loading of $5 \mathrm{MW} / \mathrm{m}^{2}$, of fusion neutrons, whereas the calculations presented in this paper use a $4 \mathrm{MH} / \mathrm{m}^{2}$ wall loading in the cylindrical geometry of Figure I-1. Lontai's conclusion was that his calculations showed his concept of the blanket would be both feasible and practical, when applied to the real geometry.

In two articles (Ref. $\# 8$ and 9 ), J.D. Lee discusses sub-critical fast fissioning blankets. His designs are spherical blankets, consisting of two zones, with an inner radius of $200 \mathrm{~cm}$ and total vidths of $100 \mathrm{~cm}$. The first $30 \mathrm{~cm}$ zone is Li depleted in Li-6, and the second zone is depleted $\mathrm{Li}$ and depleted $U$ in the ratio of $1 / 2$. Lee's results are within the constraints placed on the by'urid breeder otudied in this repnrt, except for zero' Pu produc- 
tion; however, he has made no provision for the cooling of his blankets. Lee's work, which is complimented by some more recent designs developed by. Cook and lianiscalco (Ref. mirror and laser fusion machines and does not correctly model the toroidal geometry of the hybrid breeder studied here. Lee, Cook, and lianiscalco's work does specify blankets similar in structure and materials to the hybrid of Figure I-1, and their results meet the requirements set for the hybrid breeder studied here as far as fissile production (Fu production allowed), TBR, and blanket power multiplication are concerned.

In another recent blanket design, Su, Woodruff, and McCormick (Ref.将li) discuss designs similar to those studied here for the hybrid breeder. Their machine also has the goal of U-233 production, an equilibrium concentration of $\mathrm{U}-238$ and $\mathrm{Pu}-239$, self-sufficiency in tritium production, and an initial Pu loading of 30 tonnes. su et al, report that their blanket is capable of producing 2.4 tonne U-233/yr with a blanket power of 10 clifoth) The major differences between their designs and the designs presented in this paper are the specifications of a 1.5.times smaller (volume) blanket, the use of Be as a neutron multiplier. the use of liquid lithium as a coolant, and no consideration of neutron leakage.

The survey of available literature on fusion blankets, given above, coveres the designs for fast neutron blankets. These studies were mentioned, rather than articles treating thermalized spectra, because the hybrid breeder calculations described in this paper 
used blankets with fast neutron spectra. The decision to use a fast spectrum in the blanket was made because fast spectra tend to give' the higher fissile breeding rates. Furthermore, space considerations in the blanket limit expansion spaces for the fission gases, helium, and the tritium produced. Therefore, a decision to use vented fuel pins was made to keep fuel rods short. The choice of vented fuel pins, in turn, made helium the logical choice as coolant to prevent chemiçal reactions between coolant and fuel from occuring. Any atterpt to add substantial amounts of moderator to the lattice would subtract from the space necessary for plutonium, thorium, Iithium,etc. One final reason for the fast spectrun is that a higher neutron yield is obtained from fast fissions; this makes better use of each atom fissioned in terms of neutron multiplication. Leonard and Wolkenhauer (Ref.\#12) and Jenquin, Leonard, Thomsen, and Wolkenhauer (Ref.1\%13) present discussions of thermal lattices for a fusion reactor blanket.

Before proceeding to the computational techniques and data, an explanation should be given concerning the nature and intent of the parametric calculations used as data in this paper. The parametric phase of calculations is intended to take in a wide range of possible designs. The designer is then able to infer the functional relationships of the dependent variables to the design variables. These relationships can be used to graphically map a designispace. Design constraints can then be projected on the response surface, and the region acceptable for the required design can be located. 
The method of calculation consisted of four-group diffusion theory calculations on a digital computer, with the hybrid reactor represented by a cylindrical geometry of Figure I-1. This figure represented a section of a top view of the tokamak reactor after a horizontal cut midway up the reactor. Progressing outward from the center of the reactor, the zones of interest are; the inner shield and reflector protecting the inner legs of the magnetic field coils, the inner tritium oreeding zone providing approximately $35 \%$ of the tritium bred, the two liner zones around the plasma, the banded region containing a neutron multiplier zone, fissile breed fing zone, T-breeding zone; and sometimes a neutron. reflecting zone, and an outer reflector and shield protecting: outer coils and the reactor exterior. For calculational purposes; each of these zones was considered homogenous. Note that the four blanket requirements, mentioned earlier for the hybrid, were to be satisfied by the banded region of Fig. I-1, with the exception of some tritium breeding which takes place in the inner zones of the blanket. A description of the fuel rod lattice represented by the banded region is summarized in Table I-1 and pictured in Figure I-2. Since transport theory was not being used in the calculations, except in cross section collapsing, high energy phënomena such as anisotropic scattering, resonance self-shielding, etc., are only approximately treated. The diffusion theory was used to perform a wide range of scoping calculations, as a preliminary step for more detailed calculations. The designs derived during the parametric calculations are termed reference cases, and are intended to serve as the basis for more comprehensive calculations with transport theory. 
The remainder of this paper is divided into four sections. Section two presents the computational methods employed in the parametric phase of hybrid breeder blanket design. This section also contains a list of the various blanket configurations that led to the reference designs. Section three contains a detailed compilation of the data directly leading to the three reference cases. Section four contains a discussion of the results appearing in section three. The fifth section sumarizes the results of section four, and presents a short discussion of the relationships between these results and further hybrid breeder blanket design.

The blanket designs presented here are for a stand-alone, tritium self-sufficient hybrid reactor, which would be a prolific producer of power and fissile material for sale. The designs represent the most demanding performance requirements, and the upper limit of the hybrid capability. In actual application, the hybrid may be integrated into a power park containing a number of light-water reactors, which could supply the hybrid breeder with part of its tritium and power requirement in exchange for fissile fuel. In this case less demanding hybrid design requirements would be applicable. Tritium breeding ratios less than 1.0 would be acceptable and the neutron economy in the hybrid would change substantially. 


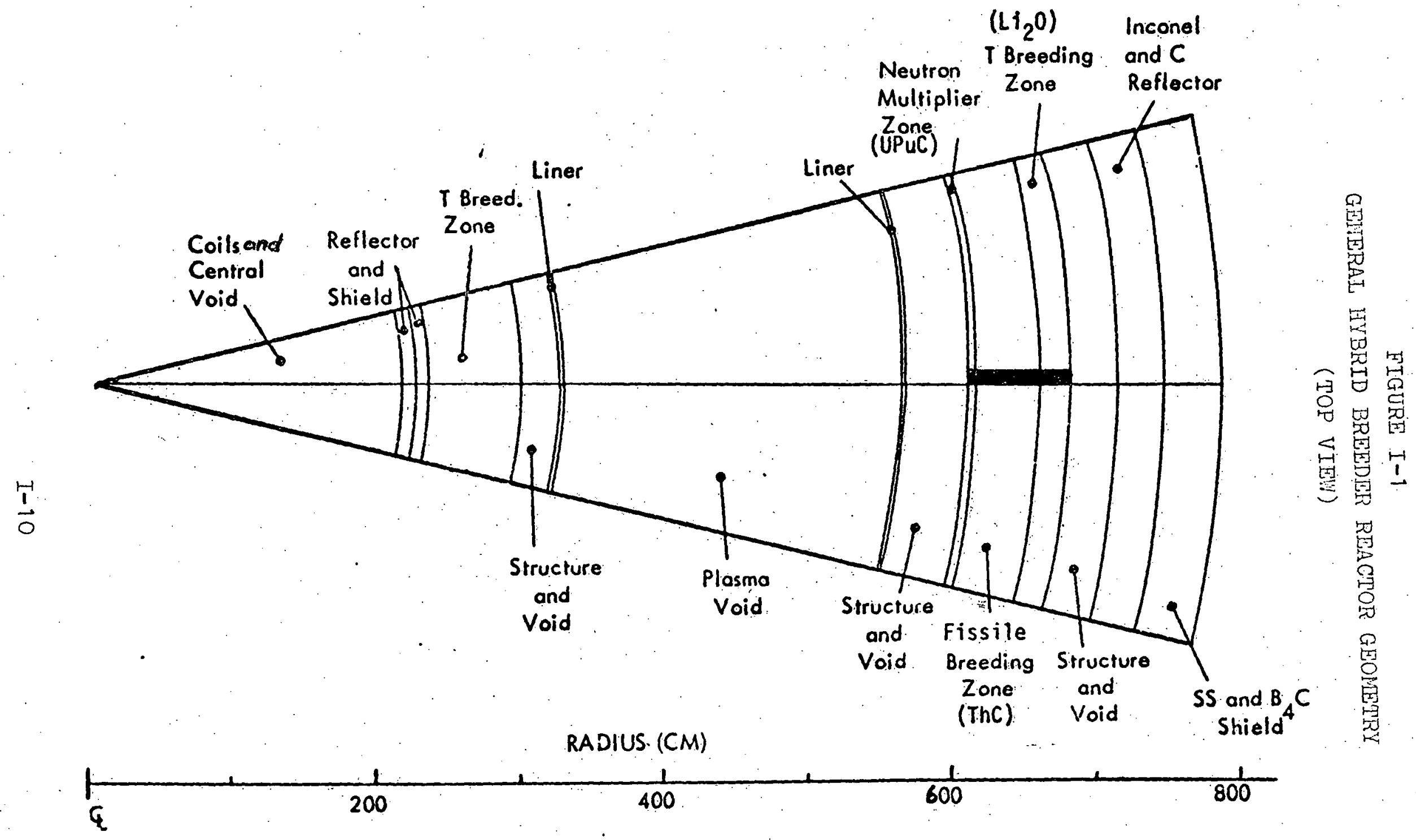


Fuel pellet diameter, d.

$=0.75 \mathrm{~cm}$

Triangular rod pitch, $P$

$=0.95 \mathrm{~cm}$

$\frac{\mathrm{P}}{\mathrm{d}_{\text {pellet }}}=1.267$

$\frac{p}{d_{c l a d}}=1.12$

Volume fraction of fuel $\quad=0.5652$

clad $=0.1507$

$\mathrm{He}$

$=\frac{0.2841}{1.0000}$

Wire wrap diameter

$=0.10 \mathrm{~cm}$

Clad thickness

$=0.05 \mathrm{~cm}$ 


\section{FIGURE I-2}

FUEL LATTICE DESCRIPTION

(VIEW ALONG MINOR RLASMA RADIUS)

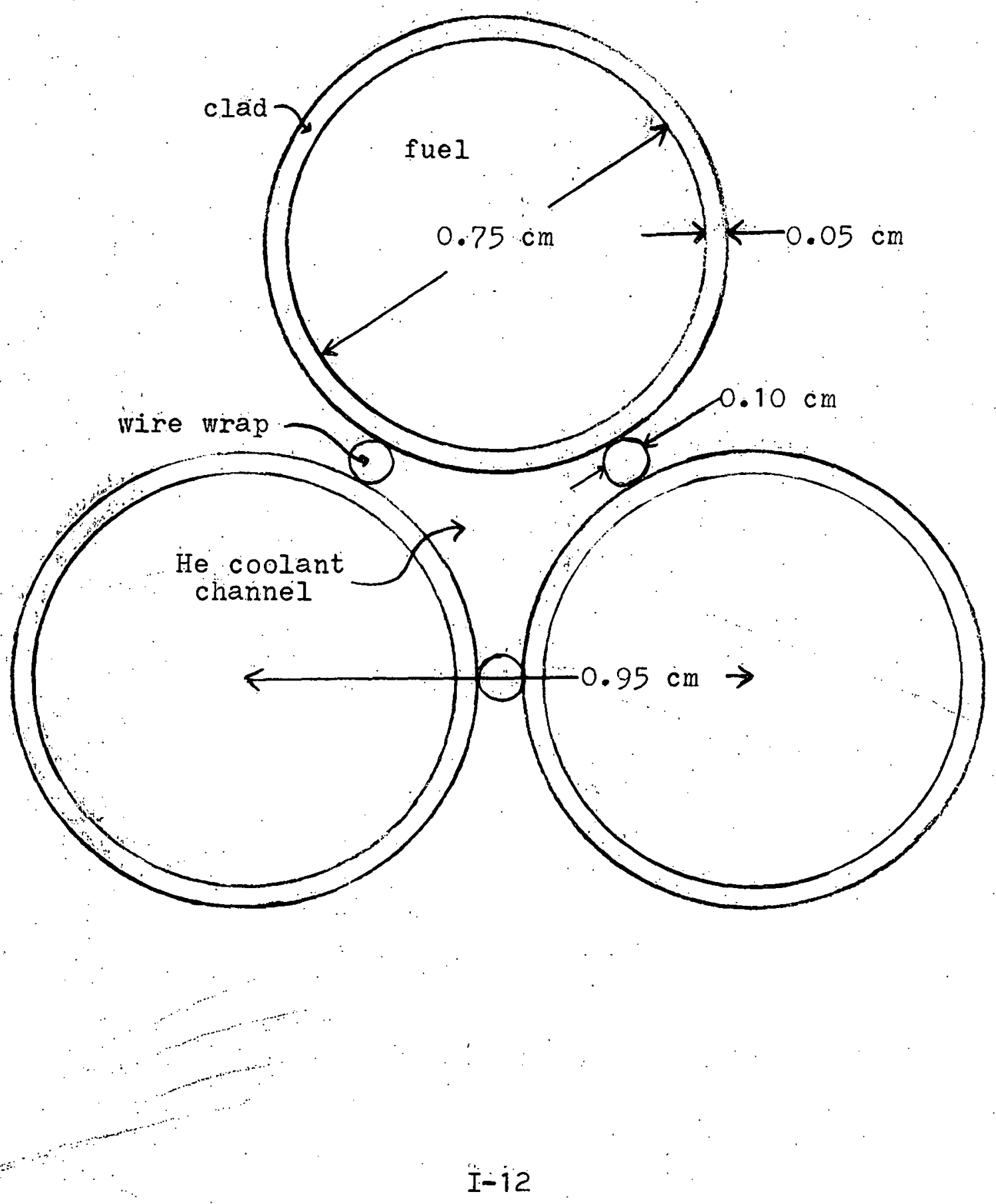


II COMPUTATIONAL TECHNIQUES AND PRELIMINARY RESULTS

The parametric study described here was carried out with the use of a method adopted from the methodology of the design of experiments $\left(\operatorname{Ref} \cdot \frac{1}{1} 14\right)$. To examine the relationship of the breeding and energy generating characteristics of the hybrid oreeder to the design variables, a number of central orthogonal designs were set up. The central orthogonal design method allows the designer to systematically examine the effects of changes in the design variables on dependent variables. The choice of the central orthogonal design method is made in order to reduce the number of combinations of design variables necessary to define a quadratic surface representing the dependent variable as a function of the design variables, and consequently reduce the number of calculations required.

Is an example of the reduction in calculations obtained by using the central orthogonal design method, consider the relationship of the tritium breeding ratio to the width of the neutron multiplier zone, the percentage of fissile material in this zone, and the width of the lithium containing tritium breeding zone. To define a quadratic response of a dependent variable to one design variable requires three values of the design variable, and to define a quadratic response surface of a dependent variable to $k$ design variables requires $3^{k}$ combinations of the design variables. This means that for the example mentioned above, the TBR wuuld have to bo determiner for the twenty-seven possible 
combinations of the three design variables in order to define the TER as a quaciratic function of them. Application of the central orthogonal design method to a design with $\mathrm{k}$ design variables, defines $2^{k}+2 k+1$ combinations of the design variables, however, their values are not chosen arbitrarily. The designer desides upon a range of interest for each design variable. The center of this range is termed the "zéro value" of the particular design variable. The half width of the range of interest is called the "scale factor," and two points are defined as the zero value plus and minus the scale factor. The central orthogonal design method defines two more points for each design variable as the zero value plus and minus a number " $\delta "$ times the scale factor. For a three variable design $\delta$ is 1.2154 , and for a two variable design $\delta$ is 1.0 so that no new values of the design variable are defined. Possible values for the three design variables of the exarnle are tabulated in Table II-1. The combinations of these variables, as designated by the central composite design method, appear in Table II-2.

After the design variable values and their combinations are defined, the designer calculates the value of the dependent variable for each corabination. For the three design variable case, the computed results are then fit to the equation;

$$
\begin{aligned}
y= & a_{11} x_{1}^{2}+a_{22} x_{2}^{2}+a_{33} x_{3}^{2}+ \\
& a_{12} x_{1} x_{2}+a_{13} x_{1} x_{3}+a_{23} x_{2} x_{3}+ \\
& a_{1} x_{1}+a_{2} x_{2}+a_{3} x_{3}+a_{0}
\end{aligned}
$$


TABLE II-1

EXAMPLE OF THE THREE VARIABLE

CENTRAL COMPOSITE DESIGN VALUES

1) NEUTRON MULTIPLIER ZONE WIDTH

\begin{tabular}{c} 
Coded Variable \\
\hline-1.2154 \\
-1.0 \\
0.0 \\
1.0 \\
1.2154
\end{tabular}

Real Variable

$\frac{\mathrm{X}_{1}}{8.923}$

10.0

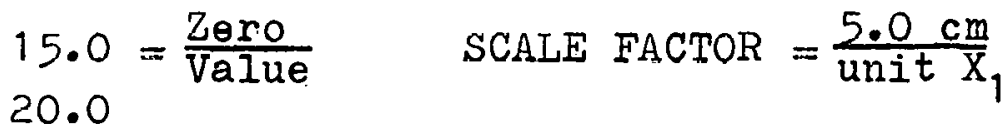

21.077

2) a/o FISSILE MATERIAL IN NEUTRON MULTIPLIER ZONE Coded Variable

$\frac{X_{2}}{-1.2154}$
-1.0
0.0
1.0
1.2154

$$
\begin{aligned}
& \text { Real Variable } \\
& \frac{\mathrm{X}_{2}}{7.5692} \\
& 8.0 \\
& 10.0=\frac{\text { Zero }}{\text { Value }} \\
& 12.0 \\
& 12.4308
\end{aligned}
$$

3) TRITIUM BREEDING ZONE WIDTH $(\mathrm{cm})$

\begin{tabular}{c} 
Coded Variable \\
\hline-1.2154 \\
-1.0 \\
0.0 \\
1.0 \\
1.2154
\end{tabular}

$$
\begin{aligned}
& \frac{\text { Real Variable }}{\mathrm{x}_{3}} \\
& \begin{array}{l}
17.846 \\
20.0 \\
30.0=\frac{\text { Zero }}{\text { Value }} \\
40.0 \\
42.154
\end{array} \quad \text { SCALE FACTOR }=\frac{10.0 \mathrm{~cm}}{\text { unit } \mathrm{x}_{3}}
\end{aligned}
$$


TABLE II-2

EXAMPLE OF THE COMBINATIONS FOR

A THREE VARIABLE CENTRAL COMPOSITE DESIGN

\begin{tabular}{|c|c|c|c|c|c|c|}
\hline \multirow{2}{*}{ CASE } & \multicolumn{3}{|c|}{ CODED VARIABIES } & \multicolumn{3}{|c|}{ REAL VARIABIES } \\
\hline & $\mathrm{X}_{1}$ & $\mathrm{x}_{2}$ & $\mathrm{x}_{3}$ & $\begin{array}{c}X_{1} \\
(\mathrm{~cm})\end{array}$ & $\begin{array}{c}x_{2} \\
(a / 0)\end{array}$ & $\begin{array}{c}\mathrm{x}_{3} \\
(\mathrm{~cm})\end{array}$ \\
\hline 1 & -1.2154 & 0.0 & 0.0 & 8.923 & 10.0 & 30.0 \\
\hline 2 & -1.0 & $\therefore .1 .0$ & -1.0 & 10.0 & 8.0 & 20.0 \\
\hline 3 & -1.0 & -1.0 & 1.0 & 10.0 & 8.0 & 40.0 \\
\hline 4 & -1.0 & 1.0 & -1.0 & 10.0 & 12.0 & 20.0 \\
\hline 5 & -1.0 & 1.0 & 1.0 & 10.0 & 12.0 & 40.0 \\
\hline 6 & 0.0 & -1.2154 & 0.0 & 15.0 & 7.569 & 30.0 \\
\hline 7 & 0.0 & 0.0 & -1.2154 & 15.0 & 10.0 & 17.846 \\
\hline 8 & 0.0 & 0.0 & 0.0 & 15.0 & 10.0 & 30.0 \\
\hline 9 & 0.0 & 0.0 & 1.2154 & 15.0 & 10.0 & 42.154 \\
\hline 10 & 0.0 & 1.2154 & 0.0 & 15.0 & 12.431 & 30.0 \\
\hline 11 & 1.0 & -1.0 & -1.0 & 20.0 & 8.0 & 20.0 \\
\hline 12 & 1.0 & -1.0 & 1.0 & 20.0 & 8.0 & 40.0 \\
\hline 13 & 1.0 & 1.0 & -1.0 & 20.0 & 12.0 & 20.0 \\
\hline 14 & 1.0 & 1.0 & 1.0 & 20.0 & 12.0 & 40.0 \\
\hline 15 & 1.2154 & 0.0 & 0.0 & 21.077 & 10.0 & 30.0 \\
\hline
\end{tabular}


where $y$ is the dependent variable, and $x_{1}, x_{2}$, and $x_{3}$ are the independent variables. The computer code PARDES II (Ref. 涪15) calculates the coefficients of the equation and five numbers related to the goodness of fit of the assuned equation form to the actual data. PARDES also extrapolates the data by allowing one to input values of the independent variables outside the range of interest. It must be remembered that these extrapolations fit a quadratic curve containing calculated data points, however a calculation at the extrapolation point may yield a different value than PARDES predicts. A detailed explanation of the contra? orthogonal design wethod appears in Anderson and McLean (Ref. $\# 14$ ).

The bulk of the neutronic calculations was carried out by the four group diffusion theory code FORGOD (Ref. sections for FORGOD vere collapsed and wixed by the codes ANISI (Ref. $\% 19$ ) and PAN (Ref. H17), from the DLC-2F library (Ref. 俕18). Vacuum spaces and helium coolant passages were given zero ahsorption, and a diffusion coefficient of $1000 \mathrm{~cm}$. The code operated in the cylindrical geometry of Figure I-1. The radii and compositions of the various zones, a 14 Hev neutron source (calculated to nodel a $4 \mathrm{~mm} / \mathrm{m}^{2}$ wall loading), the energy linits of the four groups, and a transverse dimension were the other major input parameters required for the calculations. The main output consisted of the four group fluxes at 250 radial mesh points and the absorption rates at these points. Fission power densities, total power, and the eigenvalue for the reactor, with the source turned of 1 , are also printed. Fluxes from FORGOD are 
indirectly input to the code RBURN (Ref. Fit7), with the appropriate material data to obtain the burn-up chacteristics of the blanket. RLURS output parameters include; U-233 production, Pu-239 production or consumption, thoriur consumption, and time dependent energy production rates. The tritium breeding rates are calculated from the fluxes in the lithiun regions. All the principal performance parameters obtained by these neutronics codes were then correlated to the primary design variables through the use of the PARDES code, and response surfaces were plotted.

The first configuration considered consisted of a (U,Pu)C neutron multipling and energy generating zone, a rih fissile breeding zone, and an $\mathrm{Li}_{2} \mathrm{O}$ tritiun breeding zone. All three zones have TZM clad in the lattice described in section I. A two-variable central composite design; with the atom percentage of $\mathrm{Pu}$ in the $(\mathrm{U}, \mathrm{Pu}) \mathrm{C}$ zone and the zone's thickness being the design variables, rielded the results listed in Table $I I-3$. Since a two-variable design was chosen, there are enough data points to plot response surfaces without a PARDES run. Figure II-1 shows the response of the TIR as a function of the two design variables. Similar plots could have been made for the other variables of interest. Ranges of interest can then be superimposed (for example, the TBR of 0.5 in Figure (I-1), and intersections of these regions from various plots become design points, or starting points for further computation. A PARDES run on the data used for Figure II-1 would have allowed specification of larger values of $\mathrm{a} / \mathrm{O} \mathrm{Pu}$ and $(\mathrm{U}, \mathrm{Pu}) \mathrm{C}$ zone width, and could point the way to calculations that would bring the TBR up to unity. 


\begin{tabular}{|c|c|c|c|c|c|c|}
\hline Case & $\begin{array}{l}\text { Design } \\
\text { a/o Pu in } \\
(\mathrm{U}, \mathrm{Pu}) \mathrm{C}\end{array}$ & $\begin{array}{l}\text { Variables } \\
\text { (U,Pu)C Zone } \\
\text { Width }\end{array}$ & TBR & $\begin{array}{l}\text { Blanket } \\
\text { Power }\end{array}$ & $\begin{array}{l}\text { Pu-239 } \\
\text { Prod. }\end{array}$ & $\begin{array}{l}\text { U-233 } \\
\text { Prod. }\end{array}$ \\
\hline$\#$ & $2 / 0$ & $\mathrm{~cm}$ & - & $G W(t h)$ & tonne/yr & tonne/yr \\
\hline 1 & 0.0 & 2.0 & 0.44 & $1: 2$ & 0.48 & 3.71 \\
\hline 2 & 0.0 & 6.0 & 0.46 & 2.0 & 1.47 & 3.18 \\
\hline 3 & 0.0 & 10.0 & 0.47 & 2.5 & 2.39 & 2.60 \\
\hline 4 & 5.0 & 2.0 & 0.45 & 1.5 & 0.34 & 3.83 \\
\hline 5 & 5.0 & 6.0 & 0.48 & 2.9 & 1.09 & 3.51 \\
\hline 6 & 5.0 & 10.0 & 0.51 & 4.2 & 1.88 & 3.08 \\
\hline 7 & 10.0 & 2.0 & 0.46 & 1.8 & 0.18 & 3.96 \\
\hline 8 & 10.0 & 6.0 & 0.51 & 4.1 & 0.63 & 3.91 \\
\hline 9 & 10.0 & 10.0 & 0.56 & 6.6 & 1.19 & 3.75 \\
\hline
\end{tabular}




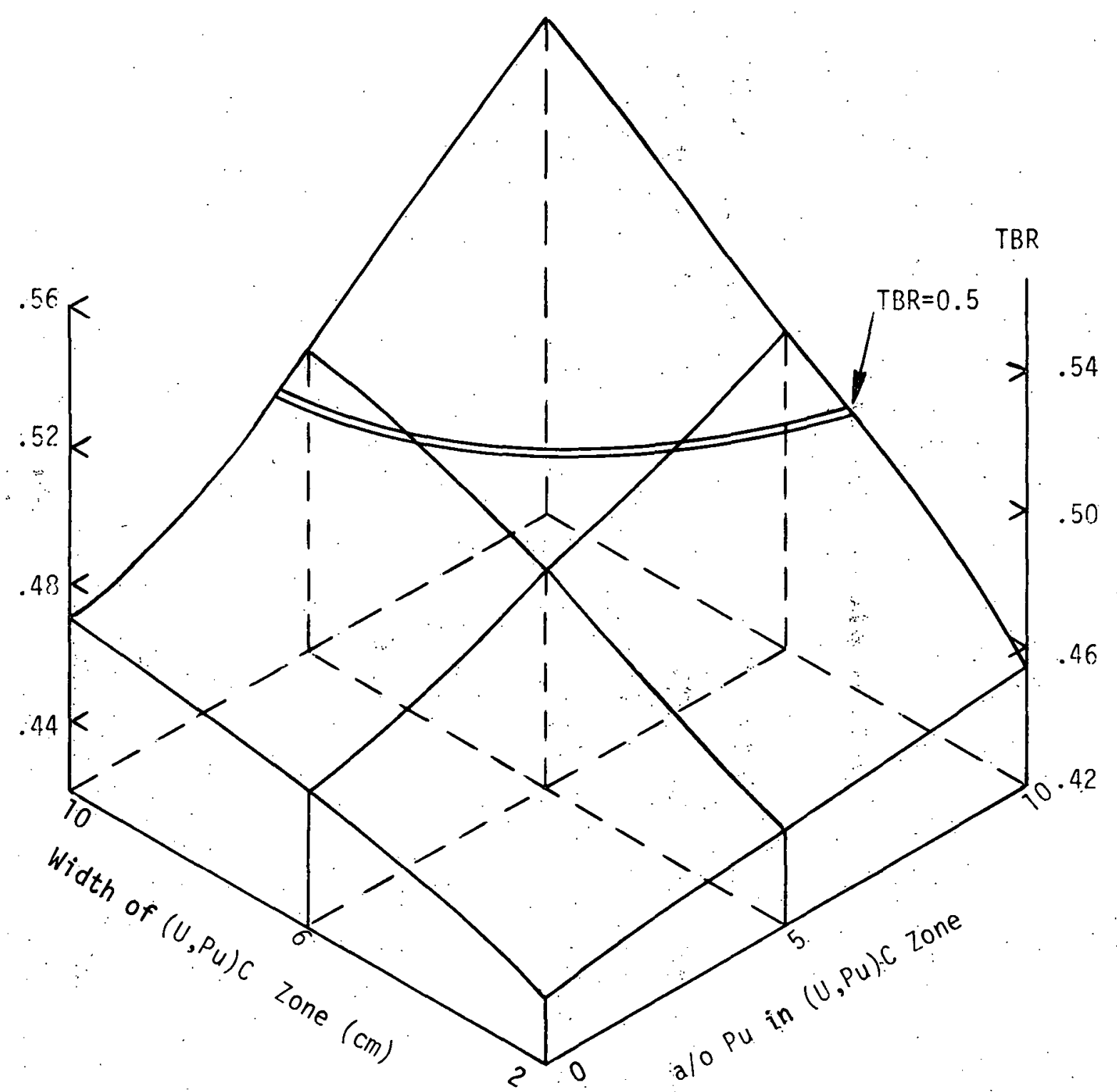

FIGURE II-1 Tritium Breeding Ratio Vs. a/o Pu and Pu Zone Width for Design \#1 
A detailed listing of all the data for each complete central composite design studied during the preliminary hybrid breeder parametric calculations would not be enlightening. The series of changes between designs (designs are listed in Table II-4) two, three, and four reflect the need to obtain 'TBR's greater than' unity. Other changes result from a restatement of the ground rules. Uranium was removed between designs one and two in order to avoid Pu-239 production. Cases two, three, four, and five form a sequence wirich leads to reference case one. Anotiner change in ground rules leads to the sequence six and seven. Uranium was allowed in the designs in an effort to create a zero plutonium producer. The production of $\mathrm{Pu}-239$ in $\mathrm{U}-238$ is to directly balance the consumption of Pu-239 in fission. Design case seven leads to the second reference case. Cases eight and nine are an effort to back track, and try designs without a clearcut multiplier region. Case nine has the substitution of stainless steel clad for THY and leads to the third reference case. In general, it can be stated that on the basis of these preliminary runs, the design requirement most difficult to meet was the self-sufficiency in tritium breeding, witiout sacrificing adequate values of fissile fuel and pover production. 
1) $(\mathrm{Pu}, \mathrm{U}) \mathrm{C}-\mathrm{ThC}-\mathrm{Li}_{2} \mathrm{O}$

Dosign Variables

1) $\mathrm{a} / \mathrm{oPu}$ in $(\mathrm{Pu}, \mathrm{U})$ zone

2) Pu zone width
TZM Clad

Zero Value Scale Factor

$5 a / 0$

$6 \mathrm{~cm}$
$5 a / 0$ per unit $x_{1}$

$4 \mathrm{~cm}$ per unit $\mathrm{x}_{2}$

Comments ;

$((\mathrm{Pu}, \mathrm{U}) \mathrm{C}$ \& ThC ) width is $50 \mathrm{~cm}$

$\mathrm{Li}_{2} \mathrm{O}$ width is $20 \mathrm{~cm}$

$$
\mathrm{TBR}_{\max }=0.56
$$

$\mathrm{U}$ in $(\mathrm{Pu}, \mathrm{U}) \mathrm{C}$ and $\mathrm{Ii}$ in $\mathrm{Li}_{2} \mathrm{O}$ are natural

2) (Th, $\mathrm{Pu}) \mathrm{C}-\mathrm{Li}_{2} \mathrm{O}-\mathrm{ThC}-\mathrm{C}$

Design Variables

1.) $\mathrm{a} / \mathrm{OPu}$ in $(\mathrm{Th}, \mathrm{Pu}) \mathrm{C}$ zone

2) $(T h, P u) C$ zone width

3) ThC zone width
TZM Clad

Zero Value

$5 a / 0$

$6 \mathrm{~cm}$

$35 \mathrm{~cm}$
Scale Factor

4.114a/o per unit $\mathrm{x}_{1}$

$4 \mathrm{~cm}$ per unit $\mathrm{x}_{2}$

5 cre per wit $x$

Comments;

( ( $\left.\mathrm{Th}, \mathrm{Pu}) \mathrm{C} \& \mathrm{Li}_{2} \mathrm{O}\right)$ width is $20 \mathrm{~cm}$

( ThC \& C ) width is $50 \mathrm{~cm}$

$\mathrm{Li}$ in Li20 is natural

$$
T B R_{\text {max }}=0.63
$$

3) $\mathrm{Li}_{2} \mathrm{O}-(\mathrm{Th}, \mathrm{Pu}) \mathrm{C}-\mathrm{ThC}-\mathrm{C}$

Design Variables

1) $\mathrm{a} / \mathrm{OPu}$ in $(\mathrm{Th}, \mathrm{Pu}) \mathrm{C}$ zone

2) $(\mathrm{Th}, \mathrm{Pu}) \mathrm{C}$ zone width

3) ThC zone width
TZM Clad

Zero Value Scale Factor

$5 a / 0$

$6 \mathrm{~cm}$

$35 \mathrm{~cm}$ 4.114a/o per unit $\mathrm{x}_{1}$

$4 \mathrm{~cm}$ per unit $x_{2}$

$5 \mathrm{~cm}$ per unit $\mathrm{x}_{3}$

Comments;

( ( $\left.\mathrm{Th}, \mathrm{Pu}) \mathrm{C} \& \mathrm{Li}_{2} \mathrm{O}\right)$ width is $20 \mathrm{~cm}$

( ThC \& C ) width is $50 \mathrm{~cm}$

$\mathrm{TBR}_{\max }=0.56$

$\mathrm{Li}$ in $\mathrm{Li}_{2} \mathrm{O}$ is natural 
TABLE II-4b

LISTING OF BLANKET DESIGNS CONSIDERED (cont.)

4) $\mathrm{Li}-(\mathrm{Th}, \mathrm{Pu}) \mathrm{C}-\mathrm{Th} \mathrm{C}-\mathrm{C}$

Design Variables

1) a/o $\mathrm{Pu}$ in $(\mathrm{Th}, \mathrm{Pu}) \mathrm{C}$ zone

2) $(\mathrm{Th}, \mathrm{Pu}) \mathrm{C}$ zone width

3) ThC zone width
TZM Clad

Zero Value

$5 a / 0$

$6 \mathrm{~cm}$

$35 \mathrm{~cm}$

\section{Scale Factor}

$4,114 a / 0$ per unit $x_{1}$

$4 \mathrm{~cm}$ per unit $x_{2}$

$5 \mathrm{~cm}$ per unit $\mathrm{x}_{3}$

Comments;

( $\mathrm{Li}$ \& $(\mathrm{Th}, \mathrm{Pu}) \mathrm{C}$ ) width is $20 \mathrm{~cm}$

( ThC \& C ) width is $50 \mathrm{~cm}$

$\mathrm{TBR}_{\text {max }}=0.76$

$\mathrm{Li}$ is $40.2 \mathrm{a} / \mathrm{o} \mathrm{Li}-6$ and is a solid zone (no clad, no void)

5) $\mathrm{Li}-(\mathrm{Th}, \mathrm{Pu}) \mathrm{C}-\mathrm{ThC}-\mathrm{C}$

Design Variables

1) $a / 0 \mathrm{Pu}$ in $(\mathrm{Th}, \mathrm{Pu}) \mathrm{C}$ zone

2) $(\mathrm{Th}, \mathrm{Pu}) \mathrm{C}$ zone width

3) a/o Li-6 in Li zone
TZM Clad

Zero Value

$35 a / 0$

$6 \mathrm{~cm}$

$23.86 a / 0$
Scale Factor

$5 a / 0$ per unit $x_{1}$

$4 \mathrm{~cm}$ per unit $x_{2}$

$13.44 a / 0$ per unit $x_{3}$

Comments;

( $\mathbb{L i} \&(T h, P u) C)$ width is $20 \mathrm{~cm}$

ThC width is $30 \mathrm{~cm}, \mathrm{C}$ width is $20 \mathrm{~cm} \quad \mathrm{TBR}_{\text {max }}=2.13$

6) $\mathrm{Li}_{2} \mathrm{O}-(U, \mathrm{Pu}) \mathrm{C}-\mathrm{TbC}$

Design Variables

1) $\mathrm{a} / \mathrm{O} \mathrm{Pu}$ in $(\mathrm{U}, \mathrm{Pu}) \mathrm{C}$ zone

2) $2 / 0$ U-235 in $U$

3) $(U, P u) C$ zone width
TZM Clad

Zero Value Scale Factor

$10 a / 0$

$5 a / 0$ per unit $x_{1}$

$0.46 a / 0$

$0.21 a / 0$ per unit $x_{2}$.

$6 \mathrm{~cm}$.

Comments;

$\left(\mathrm{Li}_{2} \mathrm{O} \&(\mathrm{U}, \mathrm{Pu}) \mathrm{C}\right)$ width is $30 \mathrm{~cm}$

Li is natural

$$
\mathrm{TBR}_{\max }=0.87
$$

ThC width is $40 \mathrm{~cm}$ 
LISTING OF BLANKET DESIGNS CONSIDERED (cont.)

7) $\mathrm{Li}-(\mathrm{U}, \mathrm{Pu}) \mathrm{C}-\mathrm{ThC}-\mathrm{C}$

Design Variables

1) $\mathrm{a} / \mathrm{O} \mathrm{Pu}$ in $(\mathrm{U}, \mathrm{Pu}) \mathrm{C}$ zone

2) $a / 0$ U-235 in U

3) $(\mathrm{U}, \mathrm{Pu}) \mathrm{C}$ zone width

TZM Clad

Zero Value

$10 a / 0$

$0.46 a / 0$

$6 \mathrm{~cm}$
Scale Factor

$5 a / 0$ per unit $x_{1}$ $0.21 a / 0$ per unit $x_{2}$ $4 \mathrm{~cm}$ per unit $\mathrm{x}_{3}$

Comments;

( Ii \& $(\mathrm{U}, \mathrm{Pu}) \mathrm{C}$ ) width is $30 \mathrm{~cm}$

Li is $40.2 a \%$ Li-6 and is a solid zone $\mathrm{TBR}_{\max }=0.98$

ThC width is $40 \mathrm{~cm}$

8) $(\mathrm{U}, \mathrm{Pu}) \mathrm{C}-(\mathrm{Th}, \mathrm{Pu}) \mathrm{C}-\mathrm{Li}_{2} \mathrm{O}-\mathrm{C}$ TZM Clad

Désign Variables

1) $\mathrm{a} / \mathrm{OPu}$ in $(\mathrm{U}, \mathrm{Pu}) \mathrm{C}$ zone

2) $a / o \mathrm{Pu}$ in $(\mathrm{Th}, \mathrm{Pu}) \mathrm{C}$ zone

Comments;

(U, Pu)C width is $10 \mathrm{~cm}$

( $T h, P u) C$ width is $10 \mathrm{~cm}$

Li ${ }_{2} \mathrm{O}$ width is $25 \mathrm{~cm}$ and $\mathrm{Li}$ is natural

$C$ width is $25 \mathrm{~cm}$
Zero Value

$10 a / 0$

$5 a / 0$
Scale Factor $6 a \%$ per unit $x_{1}$ $5 a / 0$ per unit $x_{2}$

9) $(\mathrm{U}, \mathrm{Pu}) \mathrm{C}-(\mathrm{Th}, \mathrm{Pu}) \mathrm{C}-\mathrm{Li}_{2} \mathrm{O}-\mathrm{C} \quad \mathrm{SS}-316 \mathrm{Clad}$

Design Variables

1) a/o $\mathrm{Pu}$ in $(\mathrm{U}, \mathrm{Pu}) \mathrm{C}$ zone

2) $(\mathrm{U}, \mathrm{Pu}) \mathrm{C}$ zone width
Zero Value

$10 a / 0$

$10 \mathrm{~cm}$
Scale Factor $5 a / 0$ per unit $x_{q}$ $5 \mathrm{~cm}$ per unit $x_{2}$

\section{Comments;}

$((\mathrm{U}, \mathrm{Pu}) \mathrm{C} \&(\mathrm{Th}, \mathrm{Pu}) \mathrm{C})$ width is $20 \mathrm{~cm}$

( $\mathrm{Th}, \mathrm{Pu}$ )C zone contains $5 \mathrm{a} / \mathrm{o} \mathrm{Pu}$ $T B R_{\max }=1.50$

$\mathrm{Li}_{2} \mathrm{O}$ zone width is $35 \mathrm{~cm}$ and $\mathrm{Li}$ is natural

$C$ zone width is $15 \mathrm{ch}$ 
III REFERENCE CASE CRITERIA AND RESULTS

As stated earlier the reference cases are not to be considered finished designs. They are meant to combine the good features of the calculations that lead to them. The reference cases and the central composite orthogonal design sets, immediately preceeding them, are presented in this section. The data of the three central composites are included in order to observe the interdependence of a number of the dependent variables on the design variables and each other. The reference case parameters themselves, although not refined, are a basis for calculations that more accurately describe the blanket's behavior.

The first central couposite orthogonal design set to yield a reference case is number five from the previous section. Table.III-1 compiles the data of the flititeen FORGOD and RBORN runs. This design has a number of cases with TBR's greater than 1.0 , and ajso is the only one that shows the variation in IBR with variations in the isotopic composition of lithium. Figures III-1 and 2 are plots of the TBR versus a/o $\mathrm{Pu}$ and $(\mathrm{Th}, \mathrm{Pu}) \mathrm{C}$ zone width, and a/o $\mathrm{Pu}$ and a/o Li-6 in Li respectively. Also plotted versus a/o $\mathrm{Pu}$ and $(\mathrm{Th}, \mathrm{Pu}) \mathrm{C}$ zone width are fissile power and U-233 production in Figures III-3 and 4. Pu production (consumption) is not plotted for this central composite because, at the time of the run, there was no restriction on $\mathrm{Pu}$ consumption. This hybrid breeder was being considered as a dump for the Pu-239 created in the uraniurn 
Dowered fission reactors. The choice of a reference case from this central composite takes a number of paths based on TBR, U-233, and fissile powers of Table III-1, however case 15 is the only one with an initial $\mathrm{Pu}$ inventory below 40 tonnes. This case is chosen for reference case ${ }^{\prime \prime} 1$ and the results are tabulated beside the others, in Table III-4 (following Figure III-12).

The central composite leading to reference case $t 2$ is summarized in Table III-2. This centra] composite does not have any cases that meet the requirements of $T B R>1.0, U-233>1.5$ tonne/yr. , or fissile power $\geqslant 4$ GW-th. It does approach zero Pu production and does not require a large initial $P u$ inventory in order to achieve a $T B R=1.0$. The PARDES runs of this central composite were extrapolated from $16 \mathrm{a} / \mathrm{O} \mathrm{Pu}$, in the $(\mathrm{U} ; \mathrm{Pu}) \mathrm{C}$ zone, to 50a/o. The width of the zone is slightly extrapolated also. After noting that the dependence on a/o U-235 is small (for the small values used); the TBR, $\mathrm{Pu}$ consumption, fissile power, and U-233 production are plotted as functions of $\mathrm{a} / \mathrm{O} \mathrm{Pu}$ in $(\mathrm{U}, \mathrm{Bu}) \mathrm{C}$ and $(\mathrm{U}, \mathrm{Pu}) \mathrm{C}$ zone width in Figures III-5 through 8. The reference case paraneters are chosen in the first two figures. Drawing the TBR $=1$ line taken frot Figure III-5 in Figure III-6 allows one to find the point of zero Pu production with a TBR of unity. The result is fortunate in that fissile power and U-233 production are about right, and, since the reference point does not extend much beyond the region of calculation, one can expect a fairly accurate prediction. The values of the design variables selected for the reference case are $12.5 \mathrm{a} / \mathrm{O} \mathrm{Pu}$ in (U,Pu)C; (U,Pu)C zone width of $12 \mathrm{~cm}$, and $0.5 \mathrm{a} / \mathrm{O} \mathrm{U}-235$ in $U$. The results appear in Table III-4. 
The final central composite is summarized in Table III-3. The ranges covered by the dependant variables are much larger than either of the other central composites for similar changes in the design variables. With any comparison of this set of designs to another, the change in clad from TZM to stainless steel must be recalled. The reference case is again chosen by means of the combination of the TBR $=1$ line and zero plutonium production line of Figures III-9 and 10. An acceptable TBR and Pu production does not require extrapolation beyond the range of experimental data. Figures III-11 and 12 show values of $11 \mathrm{GW}$-th fission power and 2.75 tonne/yr U-233 production. The value of the design variables used for reference case $\# 3$ are $14 \mathrm{a} / 0 \mathrm{Pu}$ in the (U,Pu)C zone and a zone width of $11.56 \mathrm{~cm}$. These are not the variables marked on the plots; they have been shifted along the zero $\mathrm{Pu}$ production line to a point where $T B R \approx 1.2$, so the reference case will not duplicate the power and uranium production stated here. The actual iesulto appear in Table III-4.

Figure III-3 points out the approximate nature of the calculations performed in the parametric phase of hybrid breeder design. In the plane of $25 \mathrm{a} / \mathrm{OPu}$ in the (Th, Pu)C zone, fissile power is increasing as the zone width is decreased from $6 \mathrm{~cm}$ to $0 \mathrm{~cm}$. Results of this kind are not uncommon when the graphed values of the design variables exceed the original ranges set on them. 
TABLE III-

COMPILATION OF DATA LEADING TO REF. CASE \#1

Li-(Th, Pu)C-ThC-C

\begin{tabular}{|c|c|c|c|c|c|c|c|c|c|c|}
\hline CASE & $\begin{array}{r}\mathrm{REAL} \\
\mathrm{a} / \mathrm{o} \cdot \mathrm{Pu}\end{array}$ & $\begin{array}{l}\text { VARIABLES } \\
\text { (Pu,Th)C } \\
\text { WIDTH }\end{array}$ & $a / 0 L i-6$ & $\begin{array}{c}\text { INITIAL } \\
\mathrm{Pu}\end{array}$ & $\begin{array}{l}\text { ENTORY } \\
\text { Th }\end{array}$ & TBR & $\begin{array}{c}\text { FISSILE } \\
\text { POWER } \\
\text { (BOL) }\end{array}$ & $\begin{array}{l}U-233 \\
\text { PROD. }\end{array}$ & $\begin{array}{l}\text { PU } \\
\text { CONS. }\end{array}$ & $\begin{array}{l}\text { EIGEN- } \\
\text { VALUE } \\
\star\end{array}$ \\
\hline$\#$ & $a / 0$ & $\mathrm{~cm}$ & $a / 0$ & tonne & tonne & atm. T/fus. & GW-th & tonne/yr. & tonne/yr. & $\cdots$ \\
\hline 1 & 28.9 & 6.00 & 23.86 & 27.1 & 637. & 0.85 & 3.60 & 3.2 & 1.90 & 0.44 \\
\hline 2 & 30.0 & 2.00 & 10.42 & 9.40 & 593. & 0.65 & 1.40 & 2.4 & 0.91 & 0.22 \\
\hline 3 & 30.0 & 2.00 & 37.30 & 9.40 & 593 & 0.84 & 0.22 & 2.0 & 0.58 & 0.16 \\
\hline 4 & 30.0 & 10.0 & 10.42 & 46.6 & 677 & 0.97 & 14.1 & 6.0 & 3.89 & 0.74 \\
\hline 5 & 30.0 & 10.0 & 37.30 & 46.6 & 677 & 1.08 & 8.03 & 4.6 & 2.76 & 0.64 \\
\hline 6 & 35.0 & 1.14 & 23.86 & 6.20 & 58.3 & 0.76 & 0.76 & 2.0 & 0.56 & 0.13 \\
\hline 7 & 35.0 & 6.00 & 7.520 & 32.8 & 631 & 0.77 & 7.37 & 4.5 & 3.55 & 0.61 \\
\hline 8 & 35.0 & 6.00 & 23.86 & 32.8 & 631 & 0.92 & 4.80 & 3.6 & 2.81 & 0.52 \\
\hline 9 & 35.0 & 6.00 & 40.20 & 32.8 & 631 & 0.98 & 3.80 & 3.3 & 2.38 & 0.47 \\
\hline 10 & 35.0 & 10.9 & 23.86 & 59.7 & 679 & $1: 42$ & 19.9 & 7.7 & 5.02 & 0.81 \\
\hline 11 & 40.0 & 2.00 & 10.42 & 12.5 & 590 & 0.67 & 1.80 & 2.6 & 1.68 & 0.27 \\
\hline 12 & 40.0 & 2.00 & 37.30 & 12.5 & 490 & 0.86 & 1.20 & 2.1 & 1.12 & 0.20 \\
\hline .13 & 40.0 & 10.0 & 10.42 & 62.2 & 663 & 2.13 & 49.7 & 12.2 & 7.49 & 0.91 \\
\hline 14 & 40.0 & 10.0 & 37.30 & 62.2 & 663 & 1.53 & 17.0 & 7.3 & 5.63 & 0.79 \\
\hline 15 & 41.7 & 6.00 & 23.86 & 38.4 & 626 & 1.00 & 6.30 & 4.1 & 4.08 & 0.59 \\
\hline
\end{tabular}

*With the fusion neutron source turned off. 


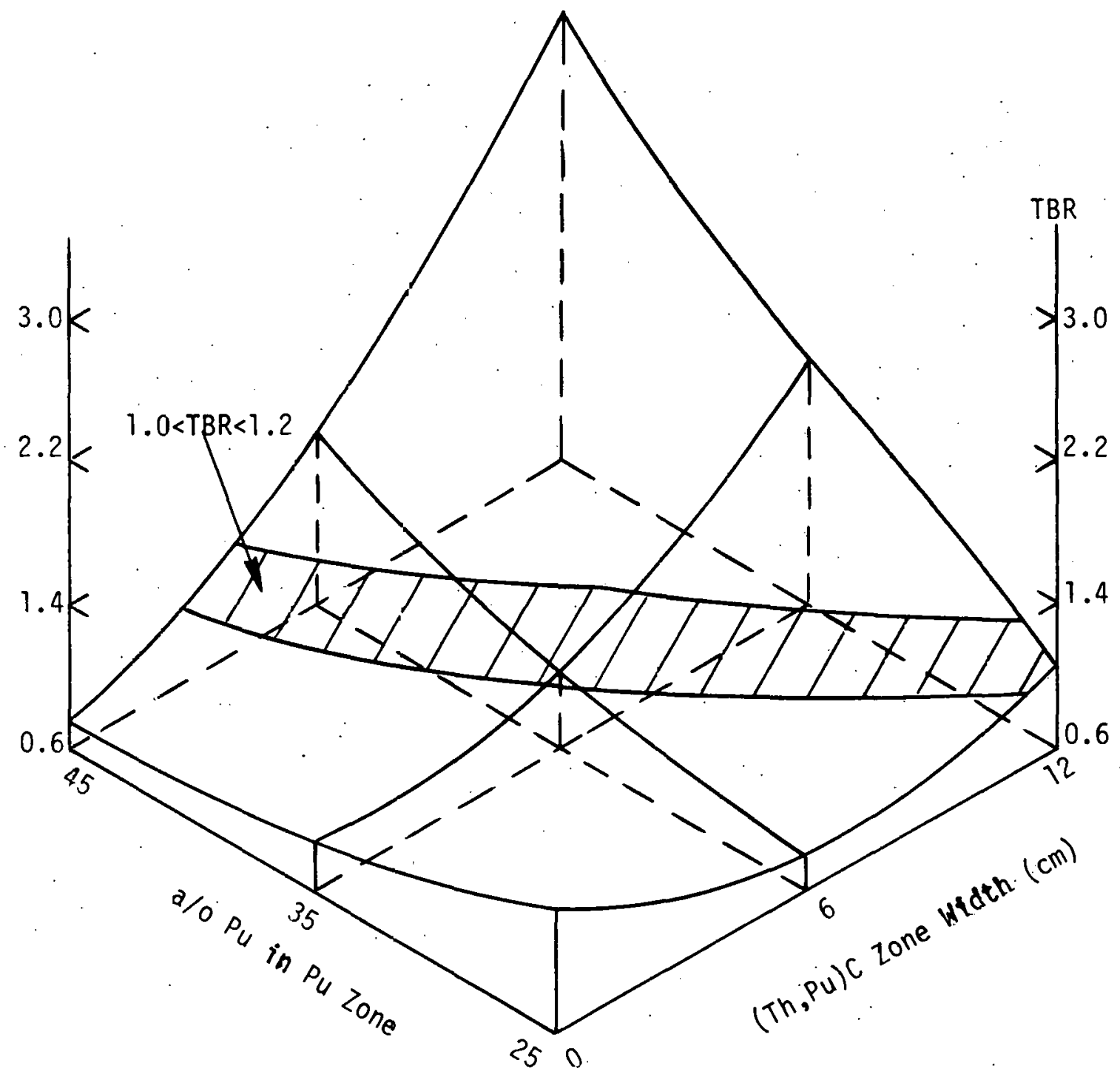

FIGURE III- 1 . TBR in a Li-(Th,Pu) C-ThC-C Blanket Vs. a/o Pu and (Th,Pu)C Zone Width, at $23.86 \mathrm{a} / 0 \mathrm{Li}-6$ in Li. 


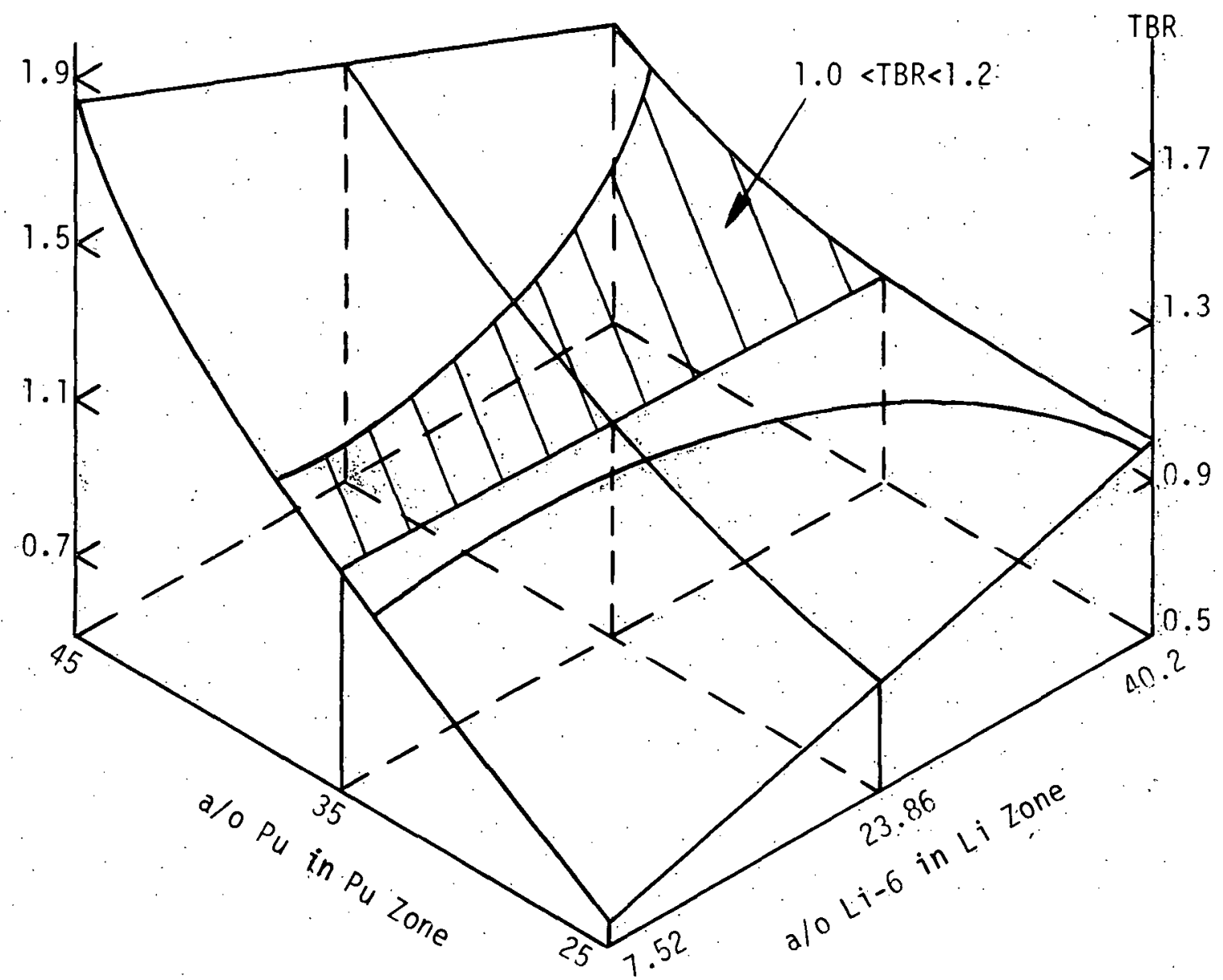

FIGURE III 2. TBR in a $L i-(T h, P u) C-T h C-C$ Branket Vs. a/o Pu and: a/o Li-6 in. Li. $(\mathrm{Th}, \mathrm{Pu}) \mathrm{C}$ Zone Width is $6 \mathrm{~cm}$. 


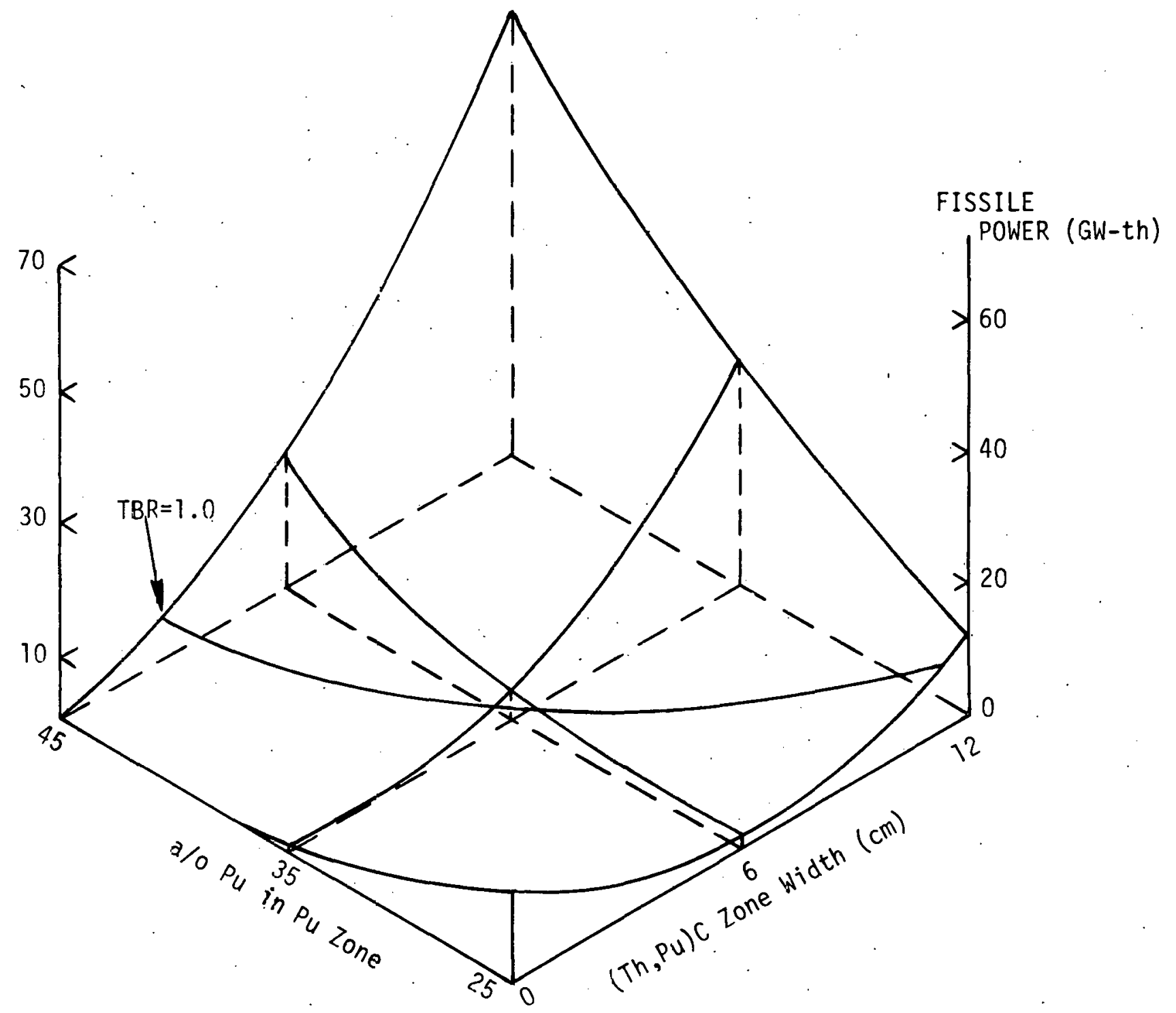

FIGURE III-3. Fissile Power in a Li-(Th,Pu)C-ThC-C Blanket Vs. a/o Pu and (Th,Pu)C zone Width, at 23.86 a/o Li-6 in Li. 


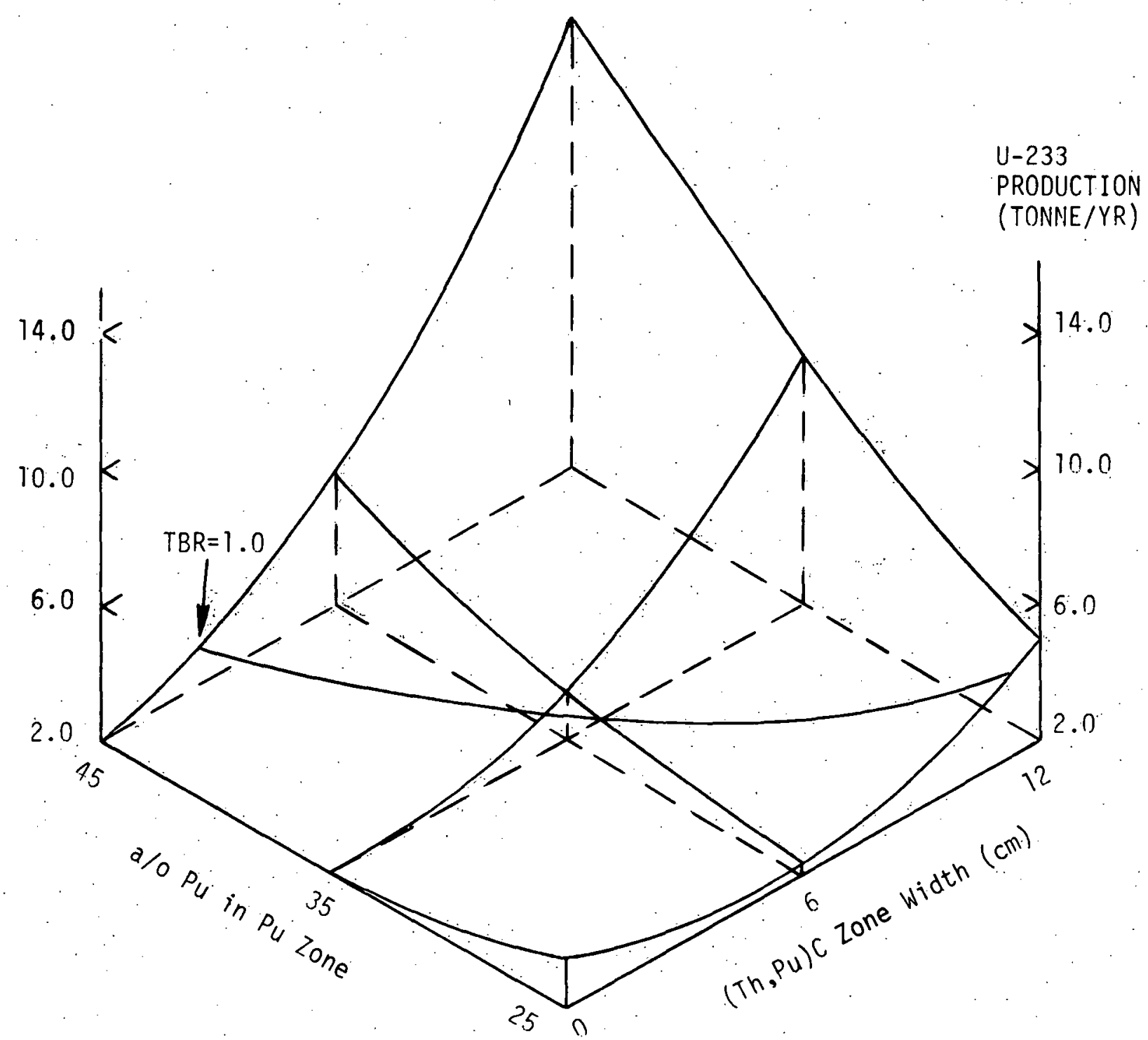

FIGURE III-4. U-233 Production in a Li-(Th,Pu)C-ThC-C Blanket Vs: a/o ànd (Th, Pu)C Zone Width, at $23.86 \mathrm{a} / \mathrm{O} \mathrm{Li}-6$ in $\mathrm{Li}$. 
TABLE III -2

COMPILATION OF DATA LEADING TO REF. CASE \#2

Li- $(U, P u) C-T h C$

\begin{tabular}{|c|c|c|c|c|c|c|c|c|c|c|}
\hline \multirow[t]{2}{*}{ CASE } & \multicolumn{3}{|c|}{ REAL VARIABLES } & \multicolumn{2}{|c|}{ INITIAL INVENTORY } & \multirow[t]{2}{*}{ TBR } & \multirow{2}{*}{$\begin{array}{l}\text { FISSILE } \\
\text { POWER }\end{array}$} & \multirow{2}{*}{$\begin{array}{l}\text { U-233 } \\
\text { PROD. }\end{array}$} & \multirow{2}{*}{$\begin{array}{c}\mathrm{Pu} \\
\text { CONS. }\end{array}$} & \multirow{2}{*}{$\begin{array}{c}\text { Eigen- }- \\
\text { VALUE } \\
\star \star\end{array}$} \\
\hline & $\begin{array}{l}\text { a/o } \mathrm{Pu} \\
\text { IN }(\mathrm{U}, \mathrm{Pu}) \mathrm{C}\end{array}$ & $\left.\begin{array}{cc}a / 0 & U-235 \\
\text { IN } & U\end{array}\right]$ & $\begin{array}{l}(U, P U) C \\
\text { WIDTH }\end{array}$ & $\mathrm{Pu}$ & $U *$ & & & & & \\
\hline$\#$ & $a / 0$ & $a / o$ & $\mathrm{~cm}$ & tonne & tonne & atm. $T /$ fus & GW-th & tonne/yr. & $\mid$ tonne/yr & --- \\
\hline 1 & $3: 92$ & .4555 & 6.00 & 3.73 & 82.7 & 0.91 & 1.05 & $0.94:$ & $=0: 03$ & 0.19 \\
\hline 2 & 5.00 & .2453 & 2.00 & 1.59 & 27.7 & 0.90 & 0.38 & 0.89 & -0.08 & 0.07 \\
\hline 3 & 5.00 & .2453 & 10.0 & 7.90 & 137. & 0.90 & 1.48 & 0.97 & -0.05 & 0.22 \\
\hline 4 & 5.00 & .6657 & 2.00 & 1.59 & 27.7 & 0.90 & 0.39 & 0.89 & -0.08 & 0.07 \\
\hline 5 & 5.00 & .6657 & 10.0 & 7.90 & 137. & 0.92 & 1.53 & 0.95 & -0.05 & 0.23 \\
\hline 6 & 10.0 & .2000 & 6.00 & 9.51 & 82.7 & 0.90 & 1.17 & 0.97 & -0.16 & 0.21 \\
\hline 7 & 10.0 & .4555 & 1.14 & 1.81 & 15.8 & 0.92 & 0.32 & 0.89 & -0.03 & 0.06 \\
\hline 8 & 10.0 & .4555 & 6.00 & 9.51 & 82.7 & 0.93 & 1.18 & 0.97 & -0.16 & 0.21 \\
\hline 9 & 10.0 & .4555 & 10.9 & 17.1 & 149. & 0.92 & 2.38 & 1.09 & -0.31 & 0.35 \\
\hline 10 & 10.0 & .7110 & 6.00 & 9.51 & 82.7 & 0.91 & 1.19 & 0.97 & -0.16 & 0.21 \\
\hline 11 & 15.0 & .2453 & 2.00 & 4.77 & 27.7 & 0.97 & 0.53 & 0.91 & 0.00 & 0.11 \\
\hline 12 & 15.0 & .2453 & 10.0 & 23.7 & 137. & 0.91 & 2.87 & 1.20 & -0.02 & 0.41 \\
\hline 13 & 15.0 & .6657 & 2.00 & 4.77 & 27.7 & 0.97 & 0.52 & 0.91 & 0.0 & 0.11 \\
\hline 14 & 15.0 & .6657 & 10.0 & 23.7 & 137. & 0.98 & 2.93 & 1.21 & -0.02 & 0.41 \\
\hline 15 & 16.1 & .4555 & 6.0 & 15.3 & 82.7 & 0.94 & 1.57 & 1.05 & +0.02 & 0.28 \\
\hline
\end{tabular}

*Initial Thorium Inventory $=637$ tonne

** With the fusion neutron source turned off. 


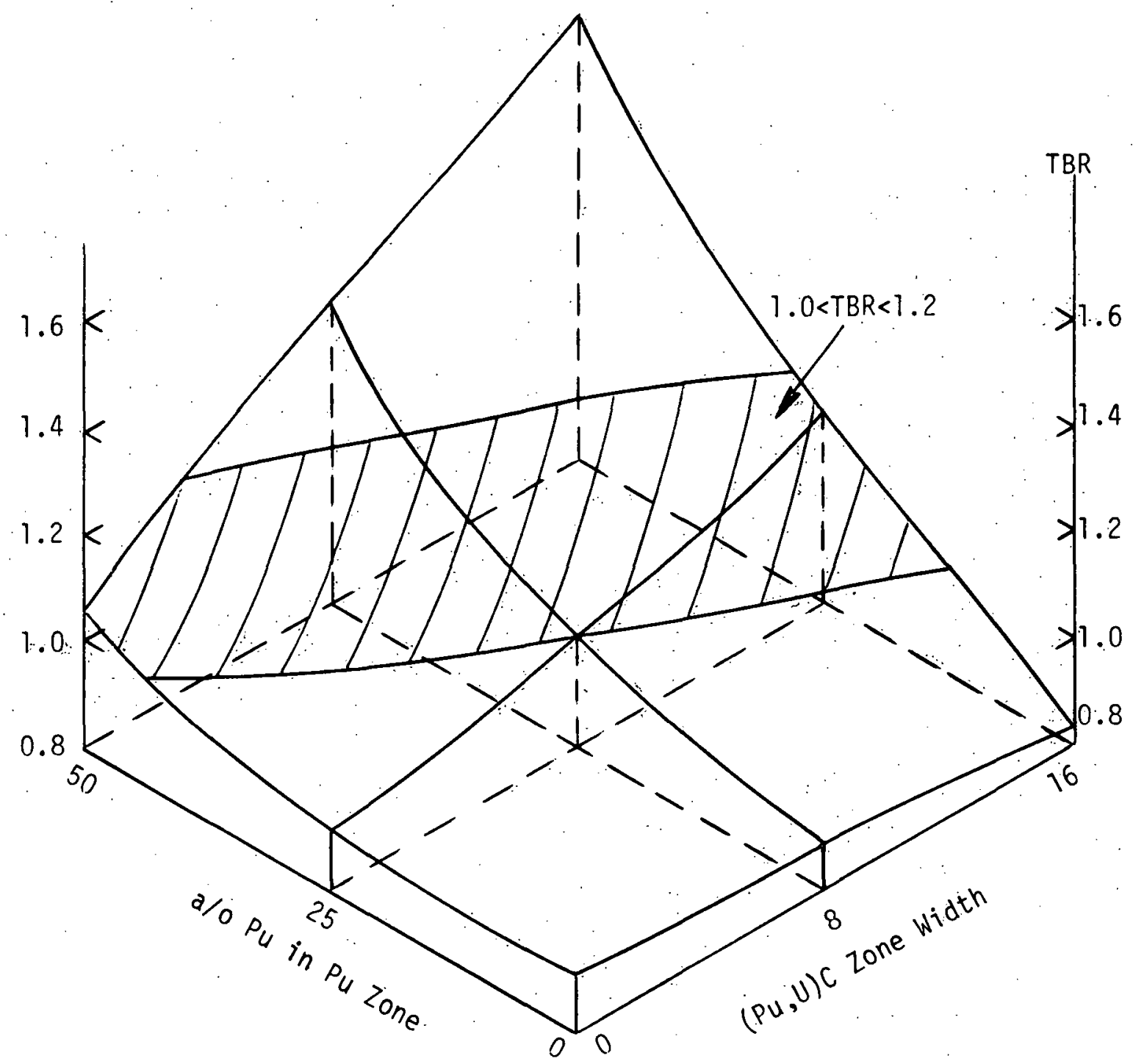

FIGURE III-5. TBR in a Li-(U,Pu)C-ThC Blanket Vs. a/o Pu:and (U,Pü)C Zone Width, at $0.5 \mathrm{a} / 0 \mathrm{U}-235$ in $U$. 


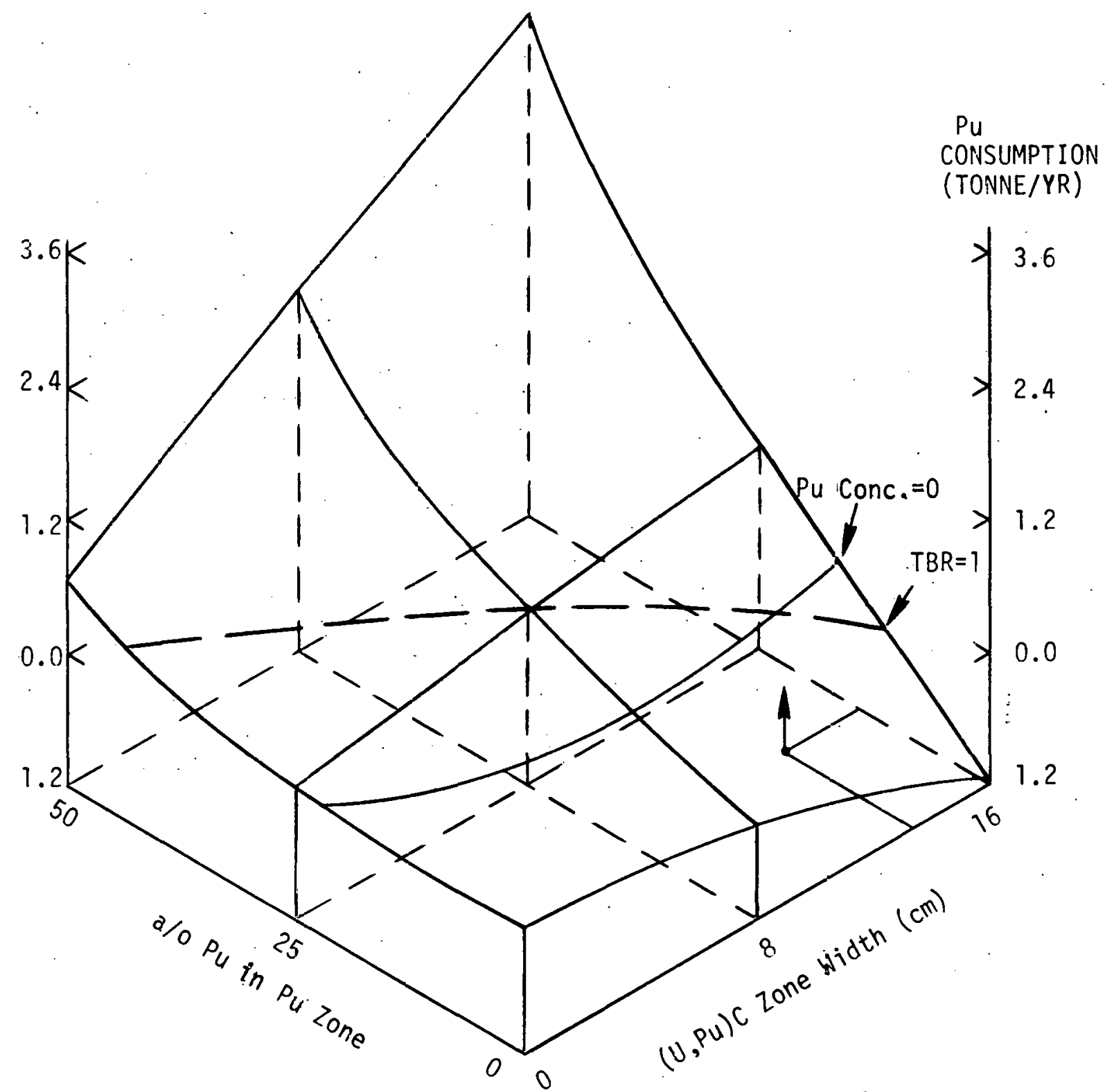

FIGURE III-6. Pu Consumption in a Li-(U,Pu)C-ThC Blanket Vs, a/O Pu and (U,Pu)C Zone Width, at $0.5 \mathrm{a} / 0 \mathrm{U}-235$ in $U$. 


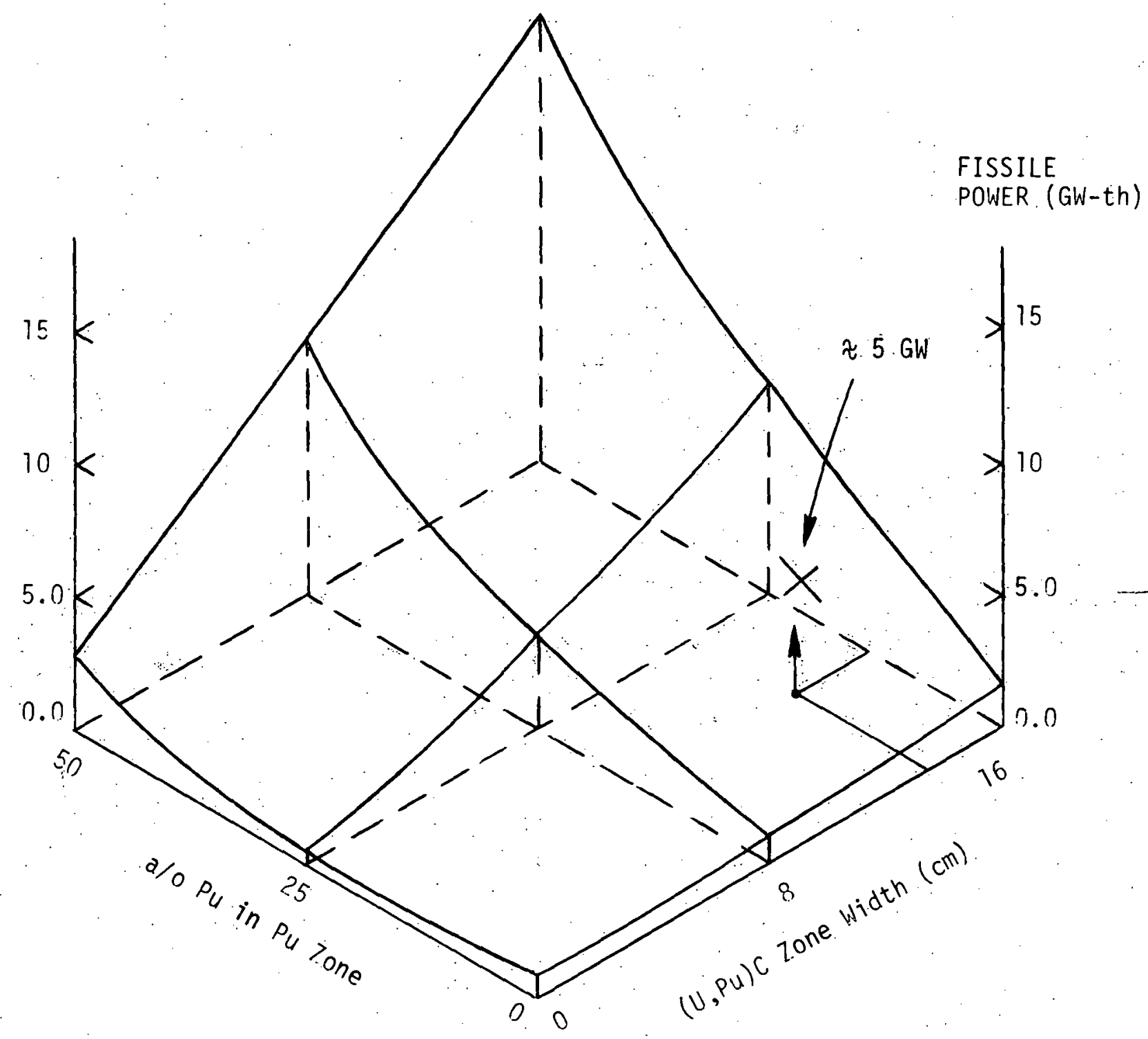

FIGURE III-7. Fissile Power in a Li-(U,Pu)C-ThC Blanket Vs. a/o Pu and (U,Pu)C Zone Width, at $0.5 \mathrm{a} / 0 \mathrm{U}-235$ in $U$. 


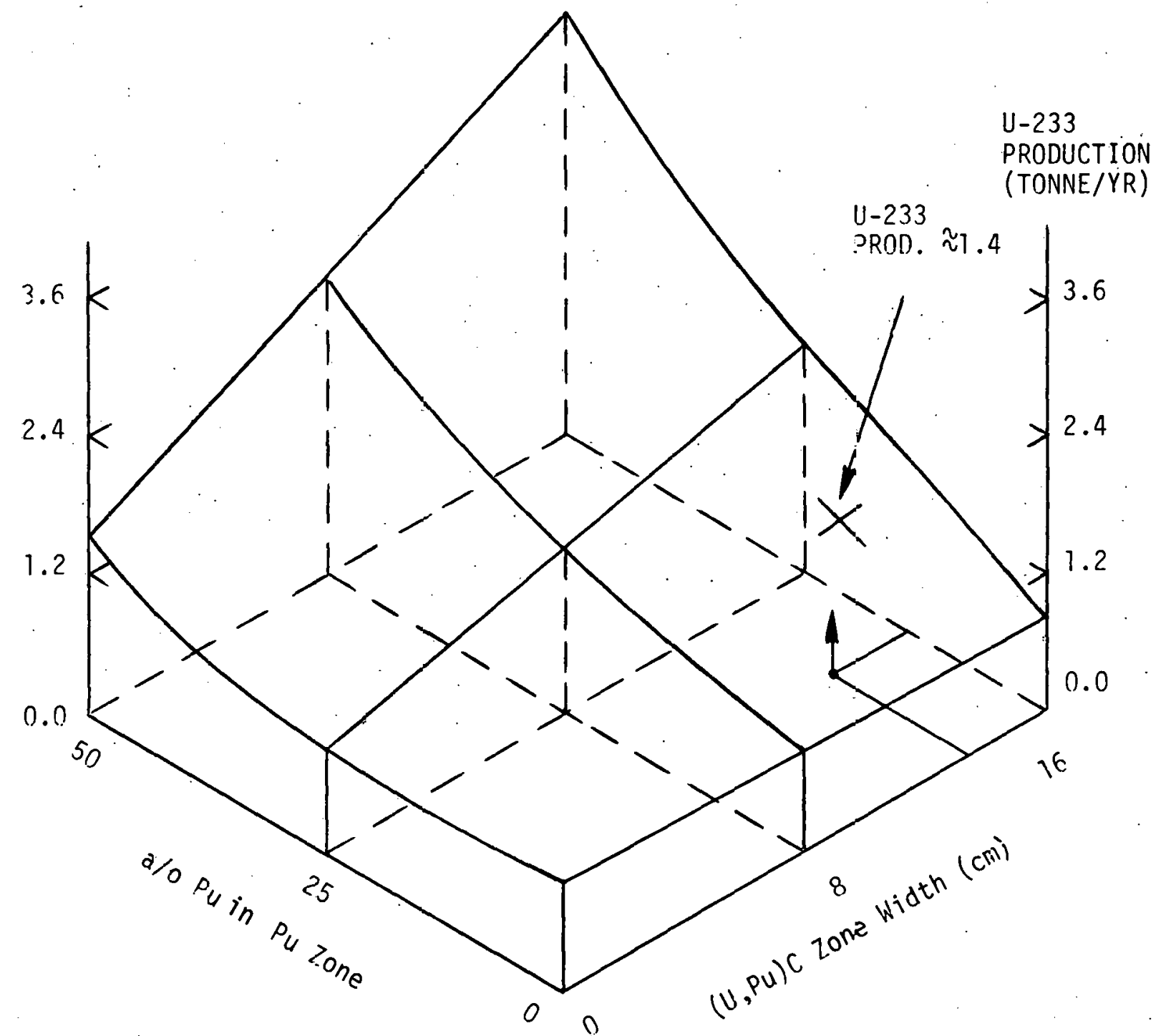

FIGURE III-8. U-233 Production in a $\mathrm{Li}-(\mathrm{U}, \mathrm{Pu}) \mathrm{C}-\mathrm{ThC}$ Blanket $\mathrm{Vs}, \mathrm{a} / \mathrm{O} \mathrm{Pu}$ and $(\mathrm{U}, \mathrm{Pu}) \mathrm{C}$ Zone Width, at $0.5 \mathrm{a} / 0 \mathrm{U}-235$ in $U$. 
TABLE III-3

COMPILATION OF DATA LEADING TO REF. CASE \#3

$(U, P u) C=(T h, P u) C=L i_{2} O-C$

\begin{tabular}{|c|c|c|c|c|c|c|c|c|c|c|c|}
\hline \multirow[t]{2}{*}{ CASE } & \multicolumn{2}{|c|}{ REAL VARIABLES } & \multirow[b]{2}{*}{$\begin{array}{l}(\mathrm{Th}, \mathrm{Pu}) \mathrm{C} \\
\text { WIDTH }\end{array}$} & \multicolumn{3}{|c|}{ INITIAL INVENTORIES } & \multirow[t]{2}{*}{ TBR } & \multirow{2}{*}{$\begin{array}{l}\text { FISSILE } \\
\text { POWER } \\
\text { (BOL) }\end{array}$} & \multirow{2}{*}{$\begin{array}{l}\text { U-233 } \\
\text { PROD. }\end{array}$} & \multirow{2}{*}{$\begin{array}{l}\mathrm{Pu} \\
\text { CONS. }\end{array}$} & \multirow{2}{*}{$\begin{array}{c}\text { EIGEN - } \\
\text { VALUE } \\
\star\end{array}$} \\
\hline & $\begin{array}{c}a / 0 \mathrm{Pu} \\
\operatorname{In}(\mathrm{U}, \mathrm{Pu}) \mathrm{C}\end{array}$ & $\begin{array}{l}(U, P u) C \\
\text { WIDTH }\end{array}$ & & $\mathrm{Pu}$ & U & Th & & & & & \\
\hline \# & $a / 0$ & $\mathrm{~cm}$ & $\mathrm{~cm}$ & tonne & tonne & tonne & $\operatorname{atm} . T /$ fus & GW-th & tonne/yr & tonne/yr. & --- \\
\hline$i$ & 5.0 & 5.0 & 15 & 15.3 & 72.3 & 214. & 0.68 & 4.90 & 2.9 & -0.21 & 0.35 \\
\hline 2 & 5.0 & 10. & 10 & 15.3 & 145 & 143. & 0.75 & 6.20 & 1.8 & -1.60 & 0.40 \\
\hline 3 & 5.0 & 15. & 5.0 & 15.3 & 219 & 71.9 & 0.80 & 7.10 & 0.8 & -3.00 & 0.45 \\
\hline 4 & 10. & 5.0 & 15. & 19.2 & 68.2 & 214 & 0.74 & 6.30 & 3.2 & +0.26 & 0.42 \\
\hline 5 & 10 & 10 & 10. & 23.0 & 137. & 143. & $=0.88$ & 9.60 & 2.2 & -0.75 & 0.54 \\
\hline 6 & 10. & 15. & 5.0 & 26.9 & 206 & 71.9 & 1.03 & 13.0 & 1.1 & -2.00 & 0.62 \\
\hline 7 & 15. & 5.0 & 15. & 23.0 & 64.7 & 214 & 0.81 & 8.10 & 3.5 & +0.85 & 0.49 \\
\hline 8 & 15. & 10. & 10 & 30.7 & 130 & 143. & 1.08 & $14: 0$ & 2.8 & +0.50 & 0.66 \\
\hline 9 & 15. & 15 & 5.0 & 38.4 & 196. & .71.9 & 1.50 & 25.0 & 1.7 & -0.07 & 0.77 \\
\hline
\end{tabular}

*With the fusion neutron source turned off, 


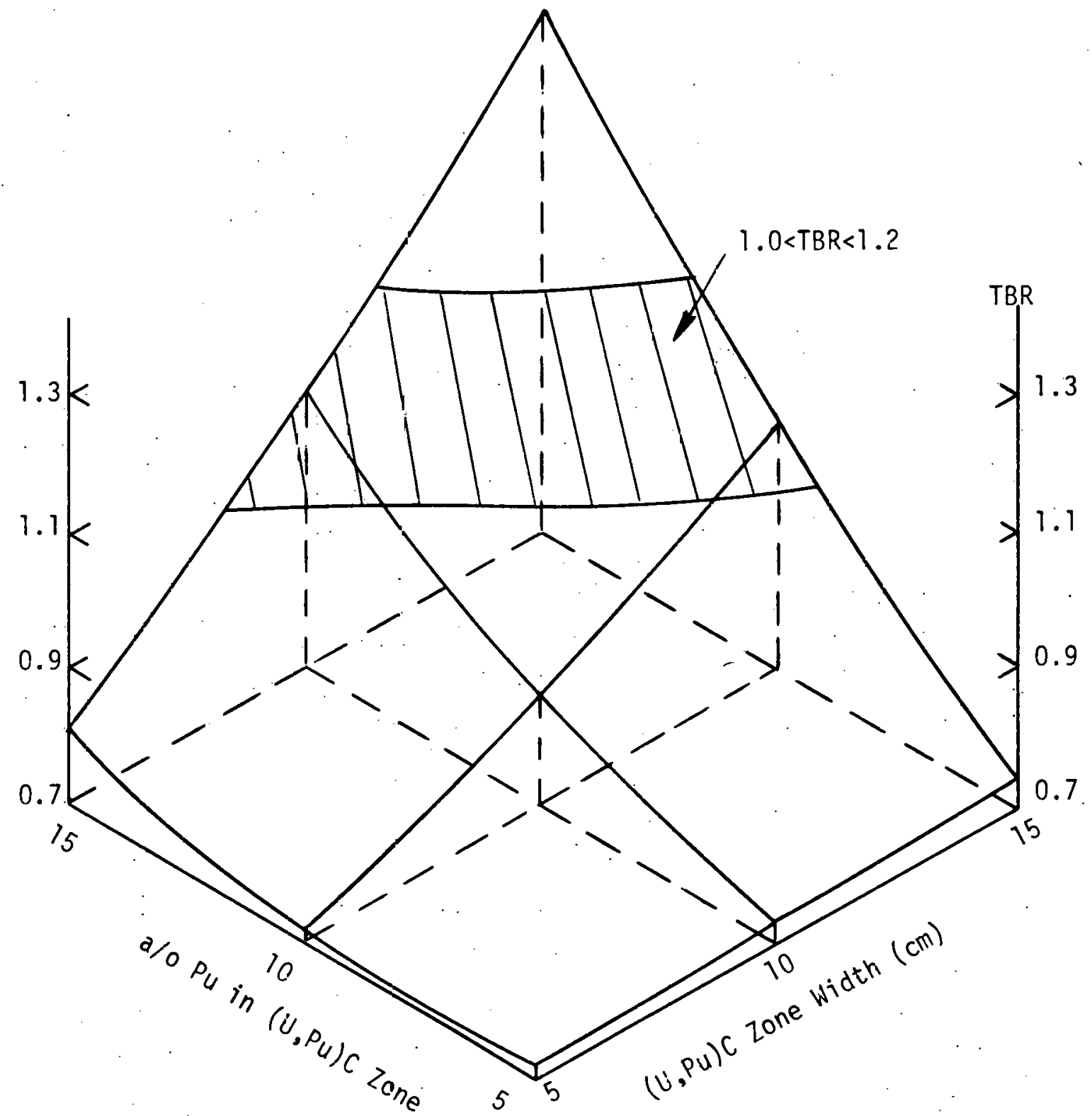

FIGURE III-9. TBR in a $(U, P u) C-\left(T h, P u I C-L i_{2} O-C\right.$ Blanket Vs. a/O Pu in $(U, P u) C$ and $(U, P u) C$ Zone Width. 


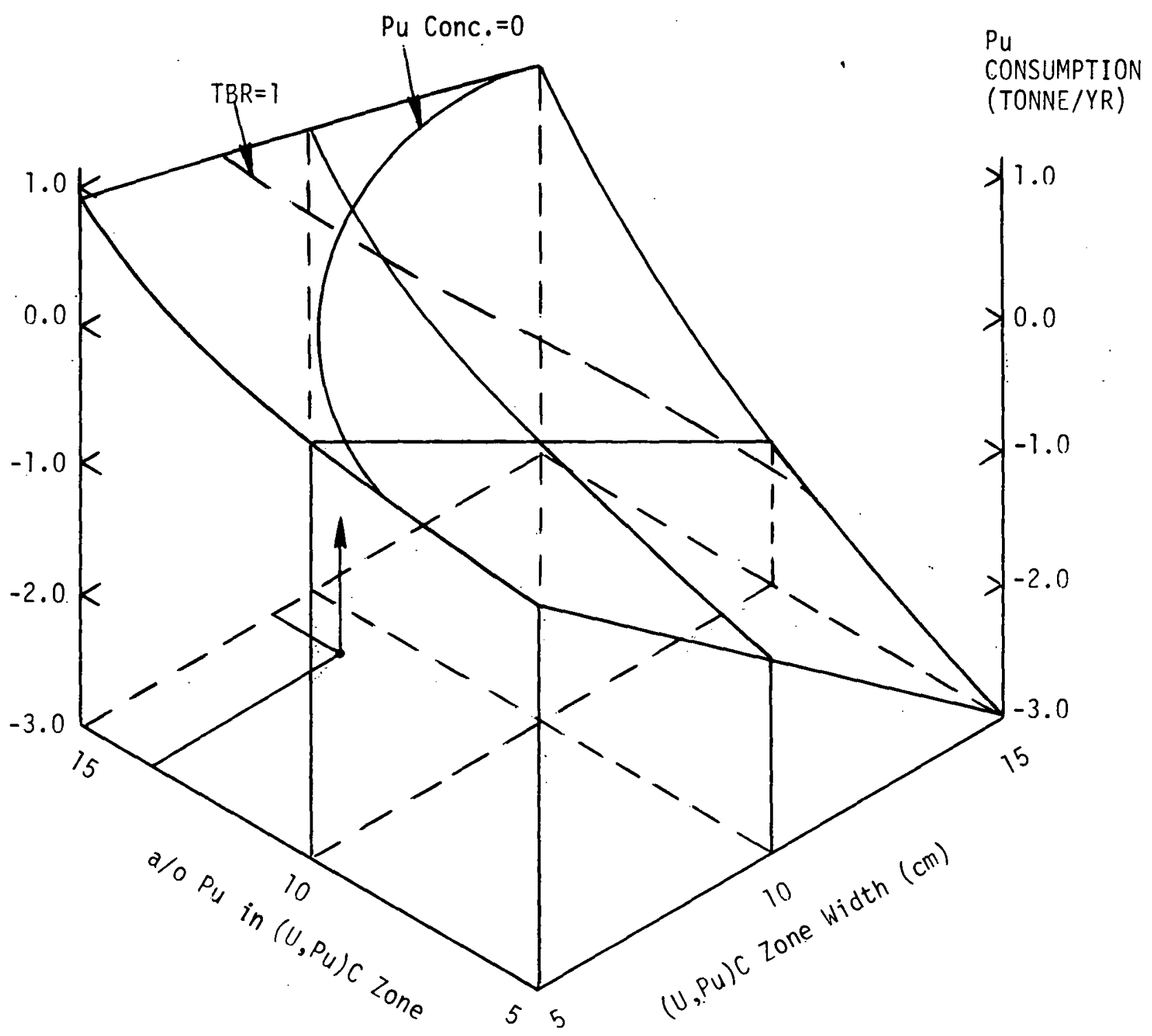

FIGURE III-10. Pu Consumption in a (U,Pu)C-(Th, Pu)C-Li ${ }_{2} 0-C$ Blanket Vs. a/o Pu in (U,Pu)C and (U,Pu)C Zone Width. 


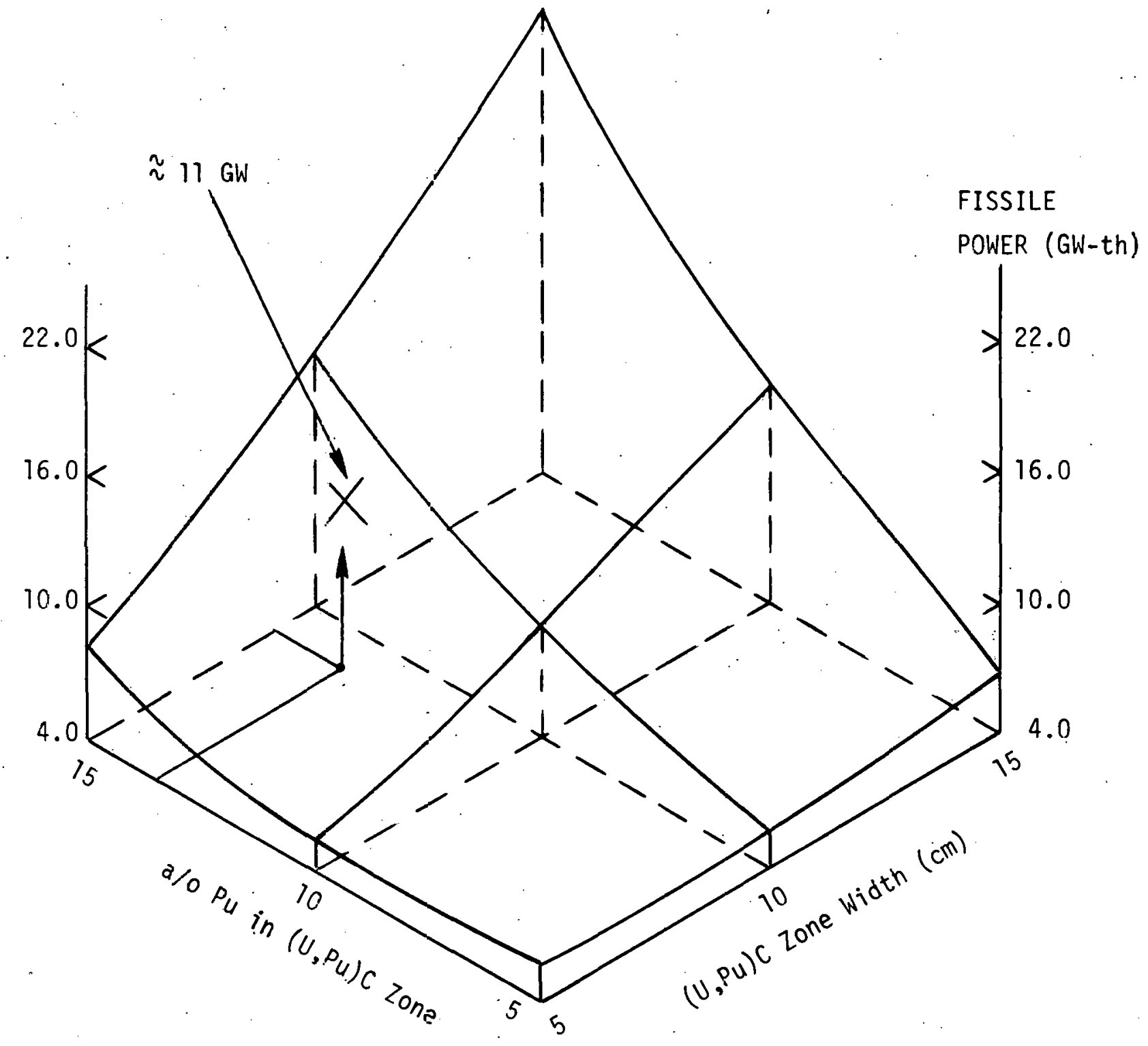

FIGURE III-11. Fissile Power in a $(U, P u) C-(T h, P u) C-L i_{2} \mathrm{O}-\mathrm{C}$ Blanket $\mathrm{Vs}, \mathrm{a} / \mathrm{O} \mathrm{Pu}$ in $(U, \mathrm{Pu}) \mathrm{C}$ and $(U, \mathrm{Pu}) \mathrm{C}$ Zone Width. 


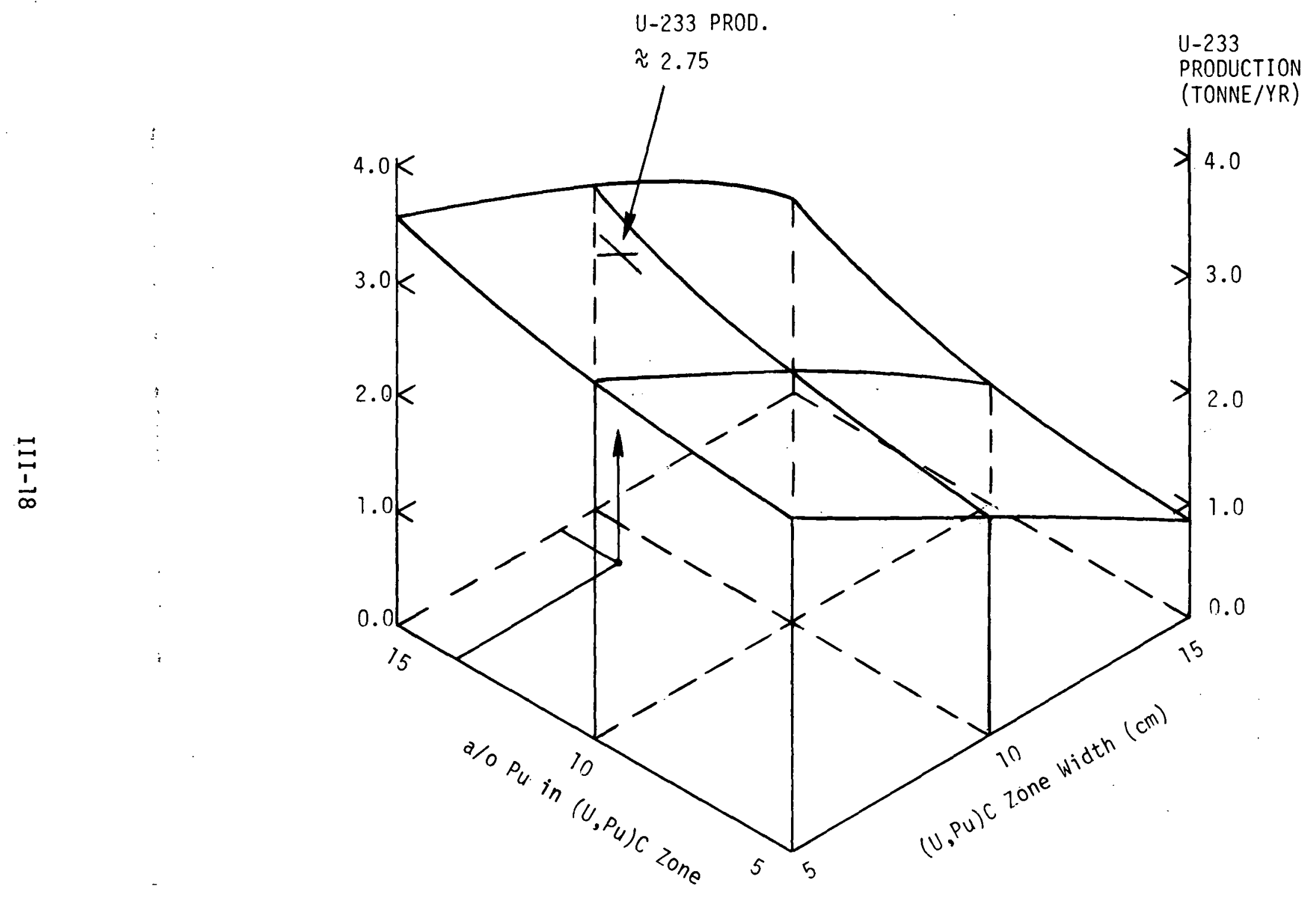

FIGURE III-12. U-233 Production in a $(U, P u) C-(T h, P U) C-L i_{2} \mathrm{O}^{-C}$ Blanket Vs, a/o Pu in $(U, P u) C$ and $(U, \mathrm{Pu}) \mathrm{C}$ Zone Width. 
TABLE III-4

SUMMARY OF REFERENCE CASE DATA

\begin{tabular}{|c|c|c|c|}
\cline { 2 - 4 } \multicolumn{1}{c|}{} & \multicolumn{3}{|c|}{ REFERENCE CASE } \\
\cline { 2 - 4 } \multicolumn{1}{c|}{ TBR } & 1.00 & 1.16 & 1.18 \\
\hline $\begin{array}{c}\text { Pu PRODUCTION } \\
\text { (tonne/yr) }\end{array}$ & $-4.08^{*}$ & 0.23 & -0.07 \\
\hline $\begin{array}{c}\text { Pu INVENTORY } \\
(\text { tonne) }\end{array}$ & 38.4 & 23.6 & 33.2 \\
\hline \begin{tabular}{c} 
EIGENVALUE \\
\hline U-233 PRODUCTION \\
$($ tonne/yr)
\end{tabular} & 0.59 & 0.43 & 0.67 \\
\hline $\begin{array}{c}\text { POWER (BOL) } \\
(\text { GW-th) }\end{array}$ & 6.3 & 3.26 & 15.9 \\
\hline $\begin{array}{c}\text { POWER (1 yr) } \\
(\text { GW-th) }\end{array}$ & 5.9 & 3.31 & 18.0 \\
\hline $\begin{array}{c}\text { BURN UP (1 jr) } \\
(\text { GW-D/tonne) }\end{array}$ & 36.8 & 5.5 & 27.8 \\
\hline
\end{tabular}

* (-) m Mans CONSUMPTION 


\section{DISCUSSION OF RESULTS}

In the course of the parametric calculations the tritiun breeding requirement was the most difficult to satisfy and still keep a realistic design. The first two reference cases can not be called realistic since the lithium zones have the idealized characteristics of a solid's density, and no consideration of cooling or structure, although if density is adjusted properly these solid zones would correctly model liquid lithium flowing through the blanket. Because the hybrid breeders will probably be required to replenish their own tritium supply, the placement and composition of the tritium breeding zone becomes a matter of concern.

The tritium breeding zone can not be thought of as a pure absorbing medium. The high energy tritium breeding reaction of Li-7 conserves the neutron through inelastic scattering. The lower energy neutron is then useful for the tritium producing reaction of Li-6, but this reaction will not conserve a free neutron. Therefore, a pure zone of Li-? wastes a low energy neutron (unless it can be easily transported to a zone that can make use of $i t)$, and a pure zone of Li-6 makes little use of the high energy neutrons that enter it. Some combination of the two isotopes will maximize tritium production, and the ratio of the two will depend on the flux spectrum existing in the region occupied by the lithium. Since reference case one uses Li-6 atom percentage as a design variable, it serves to illustrate some of the relationships between the TBR and the amount of $1 i-6$ present in the lithium zone. Figure III-1 
indicates that for large amounts of plutonium, and consequently. high elgenvalues, the tritium breeding ratio becomes large. The increased neutron multiplication, taking place as the multiplier zone approaches criticality, explains the excess number of neutrons available to the lithium. The continued increase in initial. plutonium loading of the hybrid blanket is limited by the finite amount of $\mathrm{Pu}-239$ thought to exist (presently, approximately 30 tonnes), and the cost of obtaining and processing the plutonium. Figure III-2 suggests that for a given neutron multiplier zone thickness, there should be an inverse relationship between plutonium inventory and Li-6 enrichment to achieve the largest TBR. The lithium tritium breeding cross section curves appear in Figure IV-1, and in the lowest energy group the plutonium fission cross section is the same order of magnitude as the Li-6. ( $n, t)$ reaction. The inverse relationship is a result of the nearly equal competition between $\mathrm{Li}-6$ and $\mathrm{Pu}-239$ for the limited number of low energy neutrons. The fact that the lithium zone is closer to the plasma than the plutonium zone also contributes to higher TBR's at lower Li-6 enrichments, because Li-7 can make better use of the $14 \mathrm{Mev}$ fusion neutrons. Table IV-1, summarizing the blanket spectrum averaged tritium breeding cross sections used in the calculations, shows that $\mathrm{L} 1-7$ can make ten times better use of these neutrons. The Li-7 reaction conserves a free neutron which can then enter the plutonium zone, with a larger probability of causing a fission than the 14 Mev neutron.

The effect of fission neutrons on the lithium zone is better when IV-2 


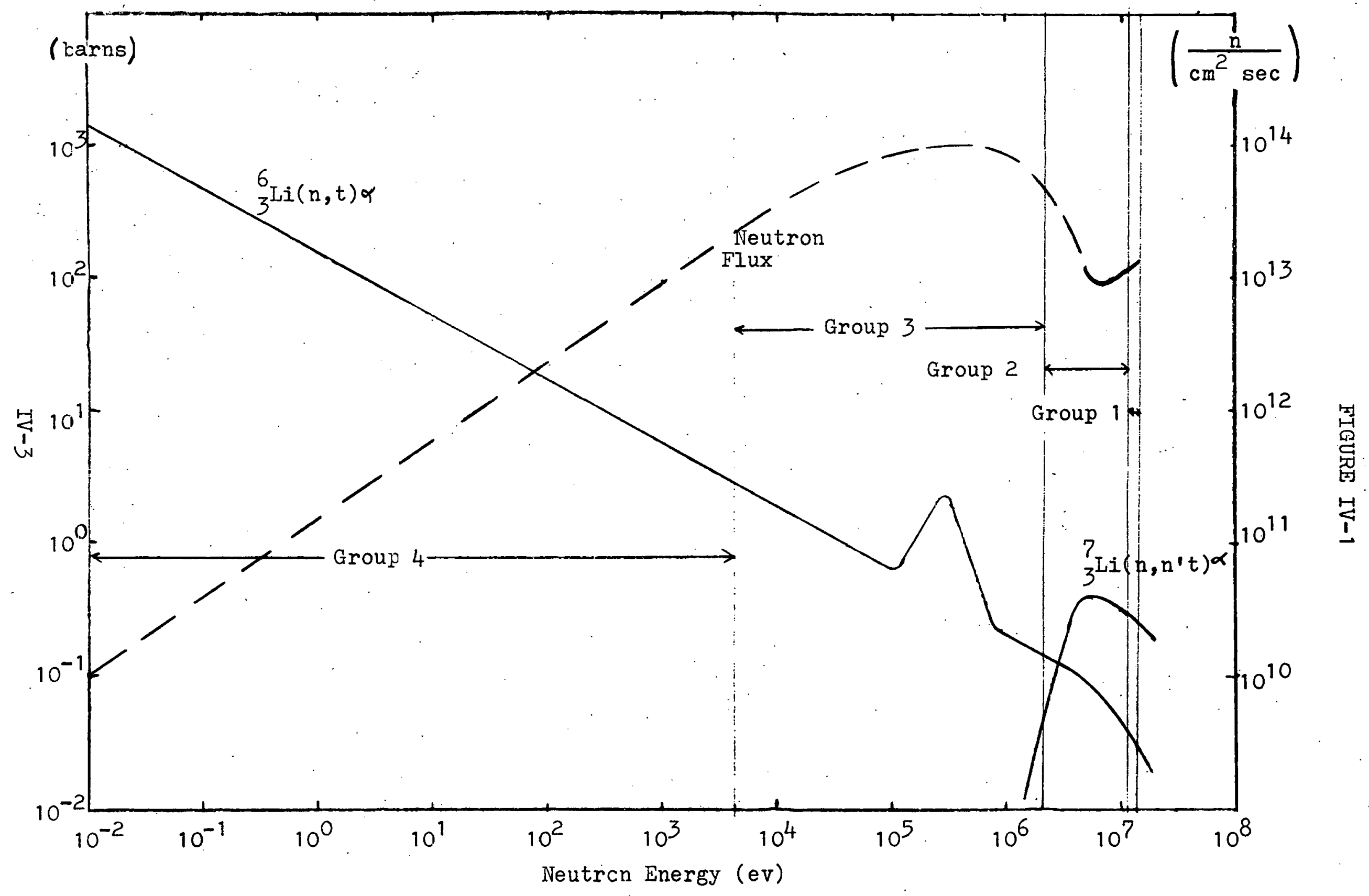

TRITIUM BREEDING CROSS SECTIONS \& BLANKET NEUTRON FLUX SPECTRUM vS. ENERGY 
the Li-6 enrichment is high. The fission spectrum, used in the calculations, placed $35 \%$ of the neutrons in group two and $65 \%$ in group three. The lithium cross sections, and a short calculation, show that the tritium breeding contributed by Li-6, from fission neutrons, is greater than that from Li-7 when the Li-6 concentration is greater than 15 a/o.

TABLE IV-1

TRITIUM BREEDING CROSS SECTIONS OF LITHIIUM BLANKET SPECTRUM AVERAGED BY ANISN

\begin{tabular}{c||c|c|}
\multirow{2}{*}{\begin{tabular}{c||c|} 
ENERGY \\
GROUP
\end{tabular}} & CROSS SECTION (b) \\
\cline { 2 - 3 } I & 0.033 & 0.33 \\
II & 0.104 & 0.244 \\
III & 0.859 & 0.0 \\
IV & 6.43 & 0.0
\end{tabular}

This reasoning leads one to suspect that the TBR graph at 45 a/o $\mathrm{Pu}$, in Figure III-2, could curve back up if the Li-6 enrichment were allowed to increase past $40 \mathrm{a} / \mathrm{o}$. Consideration of enrichment difficulties make large Li-6 enrichments undesirable due to cost increase, and calculations beyond $40 \mathrm{a} / \mathrm{o}$ were considered unnecessary. Applying these ideas to the other two reference. cases might give one cause to change them, and it may be advantagous to lower the concentration of Li-6 in order to allow more of the neutron conerping reactions in Li-7. This would decrease the TBR somewhat, but more low energy neutrons would be available to fission 
Pu-239 and breed U-233 in thorium. The third reference case uses $\mathrm{Li}_{2} \mathrm{O}$ with natural lithium. This tritium breeding zone is separated from the plasma by the zones containing fissile material, hence it sees-less of the highest energy neutrons and more of the fission neutrons. For this kind of a spectrum, $L i-6$ is a better tritium breeder. This means that a value of the TBR greater than that listed in Table III-4 could be obtained if the lithium were enriched.

The down scattering characteristics of the other elements in the lithium compound should also play some part in the compound's effectiveness as a tritium breeder. A lithium compound containing a very good moderator should contain a larger proportion of Li-6 to talie advantage of the lower energy flux spectrum that can be expected. The choice of the compound in which the lithium appears depends on the parasitic absorbtion in the compound, and the atom densities the lithium occupies in the compound. The calculations performed as a basis for this paper did not contain any form of lithiun other than metal or oxide, because data was not readily available on more exotic compounds such as plumbates or aluminates. The thermal absorbtion cross sections of lead $(180 \mathrm{mb})$ and aluminum $(243 \mathrm{mb})$, in coraparison with that of oxygen $(0.27 \mathrm{rb})$, show that the other compounds will probably have detrimental nuclear effects, however the question remalns as: to their mechanical-performance. The oxygen in dilithium oxide will probably have little effect on the tritium breeding, since the lithium atom density remains nearly the same in a solid metal zone and an oxide zone with clad 
and cooling void. Some of the sequences listed in section II progress from an $\mathrm{Li}_{2} \mathrm{O}$ zone to solid metal under the assumption that the oxygen was absorbing too many of the neutrons. The cross sections show this assumption to be in error, and the designs leading to reference case three suggest that the TZM clad was parasitically absorbing too many neutrons. It washoped that the TZM would take advantage of the high energy $(n, 2 n)$ reaction in molybenum, hovever this reaction does not seen to occur enough to offset the lower energy absorbtion reaction.

A comparison of the tritium breeding and fissile power plots of section III, point out a direct correlation between the fissile power and TBR. This is not suprising. since the power comes, for the most part, from the neutron multiplier zone, and as the power in this zone goes up, the number of neutrons available to leak into other zones also increases. It should also be noted that this direct correlation exists whether the lithium zone is in front of or behind the other zones. A comparison that may yield more information about tritium production, is that between TBR and the initial fissile inventory of the blanket. Referring to Table III-4, it is evident that more neutron multiplier ( $\mathrm{Pu}$ inventory) does not always yield a higher TBR. The TBR will depend on how efficiently the fissile fuel is used and how well it is cclpled to the lithium zone. The efficiency of the neutron multipling zone is reflected directly as the eigenvalue (k-effective of the blanket), and inversely as the fissile inventory. An indication of how well the

$$
\text { IV-6 }
$$


neutron multiplier zone and lithium zone couple, is given by a comparison of the tritium breeding: performances and the other performance variables; for example, in reference case two the TBR is satisfactory, however power and fissile production are low, This implies the neutron multiplying zone is coupled very well to the lithium zone and not too well to the other zones. A comparison of reference cases one and two show that if the lithium is to be in front of the $\mathrm{Pu}$ zone, better coupling is obtained if the $\mathrm{Pu}$ zone is wider with a lower concentration of plutonium. Comparison of these cases to reference case three indicates that good coupling can be achieved with the lithium zone behind the $\mathrm{Pu}$ zone without sacrificing good coupling to the other zones, therefore it is advantagous to put the lithium zone behind the Pu zone if a TBR $>1.0$ can be achieved.

Fron the calculations presented, the choice of clad for the fuel rods seems obvious. The switch from TZM (used for most of the parametric calculations) to stainless steel made meeting the requirements set on the performance variables much easier. Consideration of the remarks made about the calculations in section' $I$, suggests that before a final choice is made, a detailed calculation be performed to confirm the superiority of stainless steel.

One final point, concerning the calculational proceedure and how it relates to the interpretation of the results, should be made. The four group cross sections used in the diffusion theory description of this hybrid breeder blanket are neutron flux averaged by ANISN from 100 group transport theory cross sections 
using the scalar flux spectrum of Figure IV-1. This flux spectrum was generated by a cylindrical ANISN solution to one of the early blanket designs; it is taken from the center of the outer blanket. Since all of the four group cross sections are weighted using this spectrum, FORGOD solutions are best when the fluxes it generates have the approximate shape of the weighting flux. Fitting the four group fluxes from FORGOD to the spectrum in Figure IV-1 could not duplicate the curve very well. But, in the region of interest (the banded region of Figure. $I-1)$, FORGOD fluxes always peaked in the third energy"group, were slightly lower:but of the same order of magnitude in the first and second groups, and dropped one or two orders of magnitude between groups three and four. 


\section{SUMMARY}

If one wanted to build a fusion-fission reactor that would do the most (in terms of power and fissile fuel production) in the most efficient manner, the idea of breeding tritium in fission reactors, presented by Fortescue, is attractive. By removing the tritium breeding requirenent from a hybrid breeder, the initial fissile loading of the blanket could be reduced, because the poisonous effects of Li-6 are not present. Hybrid breeders may ultimately operate in this manner, however for preliminary calculations, it was considered to be a self-sufficient reactor. With this self-sufficiency in mind, the parametric phase of the hybrid breeder calculations has pointed out a number of the relationships between tritium breeding and the design variables. No gain in lithium atom density is obtained by using solid lithiur metal rather than $\mathrm{Li}_{2} \mathrm{O}$. The oxygen does not hinder blanket performance, but if lithium were present as a lead or aluminum compound, parasitic absorbtion would probably be noticably detrimental. The best coupling of the tritium breeding zone to the neutron multiplying zone, without sacrificing good coupling to the other zones, seems to be attained when the lithium is behind the other zones. Coupling also seems better when the plutonium zone is wider and less concentrated. In regions of high fission neutron spectra, Li-6 makes better use of the neutrons, however the Li-7 tritium breeding reaction conserves the neutron (but not at a high enough energy to be useful to another Li-? atom), and the proportion of Li-6 to Li-7 for a maximum TBR is not a clearcut choice. The optimuin proportion of Li-6 in the lithium compound can not be determined for a general case; it will depend on all of the other characteristics of the particular blanket 
under study. A maximization calculation should be done to determine this optimum value. Finally, the calculations show that for the fast neutron spectrum averaged cross sections erployed, the SS-316 clad is superior to TZM.

The progression to the central composite of reference case three carie about as more of these relationships became evident. Before proceeding to the more detailed calculations with the design from this reference case, one more central composite design set should be run. The power in reference case three may be too large to handle efficiently, and decreasing the amount of plutonium, while changing some zone widths and perhaps increasing the Li-6 atom density in $\mathrm{Li}_{2} \mathrm{O}$, could bring the power down without decreasing the TBR or fissile production.

Final comments concerning the hybrid breeder designs studied in this paper are again related to the question of realisn. Section IV mentioned that the solid lithium zones used in the calculations could not exist as modeled. Some consideration must be made for cooling and structural support. The $\mathrm{L}_{2} \mathrm{O}$ design must also be modified to prevent chemical reactions from occuring between the oxide and the carbides used in the multiplier and fissile breeding regions. Alate welded between zones of different composition can separate them, but helium is produced in the tritium breeding reactions, and the lithium can not be completely isolated from the coolant flow unless unvented fuel pins are used. The method of cooling, used for the designs in this paper, may also have to be 
modified. Most of the power generated in the blanket comes from the neutron multiplier region. Since this zone is only six to ten centimeters wide, the coollant flow, for the lattice of Figure I-2, may have to be very large to cool this zone, but not too large to cool the other zones. A mixture of different lattices may give fast enough coolant flow in high power regions and slower flow in low power regions. Some preliminary ideas for the blanket layout and coolant considerations appear in Ref. \#3 and its preceeding quarterly reports. Lastly, this paper mentions very little about the economic aspects of the reactor. Any decision to build commercial hybrids will rest completely on a cost versus return analyeis of a hybrid breeder reactor.

\section{ACKNOWLEDGEMENT}

The author wishes to thank the following individuale for the help he received during the course of the study: Dr.J. Jedruch for relating the techniques used to gather data presented in this paper and for his comments on the text during the course of its writting, and Drs. D. Chapin, G. Gibson, D. Klein, E. $K l e v a n s$, and $R$. Rose for their comments and suggestions regarding this paper. The author is also grateful to Prof. M.A. Schultz for his support and interest in the Cooperative Graduate Education Program. 


\section{REFERENCES}

1) "Research on Power from Fusion and Other Major Activities in the Atomic Energy Program, Jan.-June 1958," p. 221, U.S. Government Printing Office (July 1958).

2) Fortescue, P. "Comparitive Breeding Characteristics of Fusion and Fast Reactors," Science, 196, 1326, June 17, 1977.

3) Westinghouse, WFPS-TME-040, "Fusion-Driven Breeder Reactor Design Study," EPRI Contract RP473-1, Third Quarterly Progress Report, Feb. 1977.

4) Draper, E.I. and Gage,S.J.,"The Fusion-Fission Breeder: Its Potential in a Fuel Starved Reactor Economy," Texas Sym. on the Technology of Controlled Thermonuclear Fusion Experiments and the Engeering Aspects of Fusion Reactors, Austin, Texas, Nov. 20-22, 1972..

5) 'Leonard,B.R., "A Review of Fusion-Fission (Hybrid) Concepts," Nuclear Technology 20, 161, Dec. 1973.

6) Barrett,I.G., "A Fusion-Fission Reactor," KAPL-M-LGB-14, Inulls Atomic Power Laboratory (1957).

7) Lontai,I.N., "Study of a Thermonuclear Reactor Blanket with Tissile Nuclides," MS Thesis, Technical Report \#436, MIT (1965).

8) Lee,J.D., "Subcritical Fast Fission Blanket," Thermonuclear Reactor Memoranduin $; 20$, Lawrence Livermore Laboratory (Nov. 23, 1970).

9) Lee, J.D., "Noutronics of Sub-Critical Fast Fission Blankets for D-T Fusion Reactors," Proc. 7th Conf. Intersociety Energy Conversion Engineering, p. 1294, American Chem. Soc. (1972).

10) Cook,A.G. and Maniscalo, J.A., "Uranium-233 Breeding and Neutron Multiplying Blankets for Fusion Reactors," Nuclear Technology 30, 5 (July 1976). 
11) Su,S.F., Woodruff,G.I., and McCormick,J.A., "A High Gain Fusion-Fission Reactor for Producing U-233," Nuclear. Technology 29, 392 (June 1976).

12) Leonard,B.C. and Wolkenhauer,W.C., "Fusion-Fission Hybrids: A Subcritical Thermal Lattice for a D-T Fusion Reactor," USAEC Conf-7211111 (1974) 918.

13) Jenquin,U.P., Leonard,B.R., Thomsen,D.H., and Wolkenhauer,W.C.: "a Fusion-Fission Parametric Study," Annual Controlled Thermonuclear Reactor Technology Report, BNWL-1604, p.: 39 , Pacific Northwest Laboratories (1971)。

14) Anderson, V.I. and McLean,R.A., "Design of Experiments," Dekker Publ., New York, 1974.

15) Jedruch,J., written from equations presented in ".Synthetic Experiment Design Techniques in Reactor Analysis," by Krase, J.M. and Ciy-Champlin,C, APEX 303, by General Electric, November 1956.

16) Smith,H., "FORGOD Program," AECL-3671, Nov. 1970.

17) Unpublished code obtained by Dr. J. Jedruch, Westinghouse Fusion Power Systems, by personal communication with authors.

18) Oak Ridge National Laboratory.

19) Engle,W.W., "ANISN: A One Dimensional Discrete Ordinates Transport Code With Anisotropic Scattering." 